\title{
Trend-cycle decomposition for Peruvian GDP: application of an alternative method
}

\author{
Ángel Guillén • Gabriel Rodríguez
}

Received: 1 October 2013/Accepted: 13 November 2013/Published online: 6 February 2014

(C) The Author(s) 2014. This article is published with open access at Springerlink.com

\begin{abstract}
Perron and Wada (J Monet Econ 56:749-765, 2009) propose a new method of decomposition of the GDP in its trend and cycle components, which overcomes the identification problems of models of unobserved components (UC) and ARIMA models and at the same time, admits non-linearities and asymmetries in cycles. The method assumes that output can be represented by a non-linear model of unobserved components, where disturbances consist of a mixture of normal distributions. In this document, we apply thisalgorithm to Peruvian GDP using quarterly data from 1980 until 2011. As a result of this analysis, we choose the UC-CN model, which presents a mixture of normals in the disturbances of the trend and cycle component of output. The obtained trend clearly reflects the structural change undergone in the early 1990s. After a steep decrease of the trend or potential GDP as a result of drastic adjustment measures, output grew in a more stable way in the following years. In the same way, one can observe an increase in the growth rate of potential GDP from 2002 onwards, which coincides with the monetary reforms that took place at the time. Finally, the obtained cycles are consistent with the evolution of the Peruvian economy and of recession periods that have been traditionally identified. A comparison with other methods of decomposition is also provided.
\end{abstract}

This paper is drawn from the Thesis of Ángel Guillén at the Department of Economics of the Pontificia Universidad Católica del Perú. For an extended version, see Guillén and Rodríguez (2013). We thank useful comments of Paul Castillo, José Tavera, participants of the XXX Meeting of Economists organized by the Central Bank of Reserve of Peru in October 2012 and participants at the DEGIT XVIII, September 26-27, 2013 at Lima, Peru. We also thank Editor Juan Rosellón and comments of an anonymous referee.

Á. Guillén · G. Rodríguez ( $₫)$

Department of Economics, Pontificia Universidad Católica del Perú,

Av. Universitaria 1801, Lima 32, Lima, Peru

e-mail: gabriel.rodriguez@ pucp.edu.pe

Á. Guillén
e-mail: angel.guillen@pucp.pe 
Keywords Trend - Cycle - Mixture of Normals · Asymmetries ·

Non-linearities · Recessions · Filters

JEL Classification $\quad$ C22 $\cdot$ E32

\section{Introduction}

The determination of the economic cycle is an important input in the formulation of macroeconomic policy. As this is not a recent concern, several methods have been proposed to separate the trend and cyclical components of the output. Since the work of Beveridge and Nelson (1981), Nelson and Plosser (1982) and the later works of Watson (1986) and Clark (1987), a long discussion has taken place regarding the best approach to modeling an economy's cycles.

Both in the ARIMA models of the Beveridge and Nelson (1981) type, and of unobserved components (UC, hereafter) as in Watson (1986) and Clark (1987), the assumptions made end up conditioning the results of the decomposition. For example, in the first group, one assumes a negative correlation between the long and short term component, with the result that most of the variance in the output is explained by long term shocks. Whereas in the second group it is assumed that there is no correlation between long and short term components, which leads to the result that the cyclical component is just as important in explaining the fluctuations in the economy.

Morley et al. (2003) propose a model of unobserved components that reconciles both positions, depending on the assumed degree of correlation. However, despite this improvement in the specification, the resulting cycles are symmetrical, which bears no relation to the ample evidence in favor of non-linearities and asymmetries in output as shown in Neftci (1984), Friedman (1993) and Diebold et al. (1993).

In order to model these non-linearities, models of regime change are used, such as Hamilton (1989) and the "plucking" model of Kim and Nelson (1999a). These models have an advantage with respect to the previous ones, in that they estimate the probability of being in a recession period and capture the asymmetries in output. However, they assume that the transition from one regime to another is characterized by following a Markov process. This can be a very strong assumption when dealing with emerging economies, since they have undergone large structural changes that are unlikely to be repeated.

In the case of the Peruvian economy, several authors have tried to model the behavior of GDP by different methods, which can be classified as linear and nonlinear. Among the former, Cabredo and Valdivia (1999) and Seminario (2007) employ statistical filters and aggregate production functions; Miller (2003) uses a structural VAR; and Rodríguez $(2010 \mathrm{~b}, \mathrm{c})$ proposes a multivariate unobserved components model. Regarding the latter, Rodríguez (2010a) applies the Hamilton (1989) model, the STAR of Teräsvirta (1994) and the "plucking" model of Kim and Nelson (1999a).

The applied linear models do not contemplate asymmetries in the behavior of GDP, and thus the generated cycles overestimate or underestimate the output gap, 
especially in the periods before 1990, when Peruvian GDP growth was very irregular. On the other hand, the estimation of Rodríguez (2010a), despite of taking into account non-linearities in output, does not identify correctly the recession periods after 1990. One plausible explanation for this is that the application of the Hamilton (1989) model, or in general the use of a Markov process, are not very useful for Peruvian GDP, which underwent important structural changes in the early 1990s.

Perron and Wada (2009) propose a new method of GDP decomposition in trend and cycle, which overcomes the identification problems of UC and ARIMA models, while simultaneously admitting non-linearities and asymmetries in cycles. It is assumed that the data-generating process of output can be represented by a nonlinear model of unobserved components, where shocks are composed by a mixture of normal distributions.

This specification admits structural changes that can be reflected in sudden changes in the trend of output. For example, changes in the level that could be caused by large scale shocks but low probability of occurrence, whereas most of the time the dynamic of the trend is led by shocks of lesser magnitude. The assumption behind this behavior is the existence of regimes of high and low variance, each of them with a normal distribution and associated with a likelihood of occurrence. On the other hand, in contrast to the Hamilton (1989) model, the transitions between regimes are not determined by a Markov process, and hence the process of decomposition is well adapted to the structural changes that output may be subject to.

In view of these advantages, it is convenient to apply the method of Perron and Wada (2009) for the decomposition of Peruvian GDP between trend and cycle. First, we attempt to capture the effect of non-linearities and asymmetries in output as documented by Rodríguez (2010a). And second, to capture the structural change effect that took place in the early 1990s when important structural reforms were enacted. According to evidence reported by Castillo et al. (2007), these reforms ushered in a phase of more stable growth of the economy. It is important to highlight the fact that previous estimations have not been able to associate that structural break with a behavior in the trend or the cycles of output.

The applied method features great flexibility and allows the modeling of structural breaks in output trend, which reflects potential output; or in the slope, which measures the long term growth rate. Furthermore, it allows asymmetrical behaviors in the output cycles. For this reason, we set out seven models with each of the possible specifications.

This exercise assumes the risk of generating cycles that are sensitive to the type of specification. For example, if it is assumed that there are high and low variance regimes related only to the output trend, one obtains a predominance of long term shocks on output variations; instead, if one admits also regimes with high and low volatility in the cyclical component, both long term and short term shocks are relevant. For this reason, a model validation process is carried out by an assessment of residuals, and also a model selection process by using information criteria and a likelihood ratio test following the specification by Davies (1987). 
From this analysis, we opt for the UC-NC $\operatorname{model}^{1}$, which presents a mixture of normals in the disturbances of the trend and cyclical components of output. The thusly obtained trend clearly reflects the structural change that took place in the early 1990s. After a sharp decrease in the trend or potential GDP, a result of the severe adjustment measures that were carried out, GDP grew in a more stable fashion in the following years. In a similar way, an increase in the potential GDP growth rate can be observed from 2002 onwards, which coincides with the enactment of monetary reforms. Finally, the obtained cycles are congruent with the evolution of the Peruvian economy and with the recession periods that have been traditionally considered.

The remainder of this document is structured as follows. Section 2 contains a review of the literature and the rationale behind the chosen method, Sect. 3 describes the applied methodology and presents a brief analysis of the data, Sect. 4 contains the results and Sect. 5 presents the conclusions.

\section{Literature review}

A first approximation in cycle analysis was given by Burns and Mitchell (1946), who compiled the first timeline of business cycles for the United States. The cycle was defined as the expansion of several economic activities, followed by a recession and then a period of recovery. Several macroeconomic indicators were used and the simultaneous switch of signs was analyzed. A cycle was established for each indicator and an index was built for the whole economy's cycles. Subsequently, $\mathrm{NBER}^{2}$ applied this methodology for the classification of cycles.

The main disadvantage of this classification is the lack of measurement of the economic cycle and the delays in the identification of the recessionary cycles in a rapidly growing economy. Regarding the first point, Fellner (1956) estimates the business cycle as the residual between a series and its trend, where the trend is deterministic and is modeled as a polynomial that depends on time. As to the second point, Zarnowitz and Boschan (1977) provide a new approach, identifying "growth cycles" that have a lead with respect to the NBER chronology.

Beveridge and Nelson (1981) reject the imposition of a deterministic trend as the trend component of a series. They suggest that the trend component follows a stochastic process that may not necessarily be stationary. By means of a stationary ARIMA model in first differences, they estimate the trend component, while the cyclical component is estimated by residual. This procedure is applied to all macroeconomic indicators used by NBER for the classification of cycles. Each of the series is modeled as an $\operatorname{ARIMA}(p, 1, q)$ process, using the Box and Jenkins (1976) method for the identification of the parameters. Finally, a composite index is assembled by weighting the obtained cycles and then compare the results with the

\footnotetext{
${ }^{1}$ UC-CN means unobserved components model with mixtures of normals in the disturbances of the cycle (C) of output, and of the trend level $(\mathrm{N})$.

2 The National Bureau of Economics Research is the institution in charge of establishing the duration of economic cycles in the United States.
} 
NBER chronology and that by Zarnowitz and Boschan (1977). Their results show a lead in the cycle periods and the same duration in the expansions and recessions. This is a contrast to NBER, which marks longer expansionary cycles and shorter recession periods.

Nelson and Plosser (1982) maintain the idea that output is led by a stochastic trend, and they analyze the principal yearly macroeconomic series of the United States from 1909 to 1970. They apply a unit root test (Dickey and Fuller 1979; Said and Dickey 1984), and conclude that the majority of the series, including GDP, do not reject the hypothesis of unit root. That is, the series are not stationary around a trend. Hence, the permanent or trend component follows a random walk, whereas the cyclical component follows a stationary behavior. In order to identify these components, they suggest a model of unobserved components, estimating the cycle through a signal extraction method (Friedman 1957; Muth 1960). Their results indicate that the real perturbations that affect the permanent component of output are the main sources of economic fluctuations. This idea was reinforced by Campbell and Mankiw (1987), who find persistence in the long term shocks on US GNP; according to these authors, an innovation of $1 \%$ on real GNP is associated with an increase of more than $1 \%$ in the long-term trend, and from that a negative correlation between the trend and cyclical components is drawn.

One feature of the decomposition by ARIMA models is that the identification of the trend and the cycle is only possible if a negative correlation between real innovations and the transitory cycle is assumed. Another form of decomposition involves the use of unobserved component models (UC), where identification implies a null correlation between the innovations of the cyclical and the trend components. From this perspective, Watson (1986) studies the annual series of GNP, available income and the consumption of non-durable goods in the United States from 1950 to 1985 . GNP is modeled as an $\operatorname{ARIMA}(0,1,1)$, income as an $\operatorname{ARIMA}(0,1,4)$ and consumption as an $\operatorname{ARIMA}(0,1,0)$. Similarly, each series is modeled in non-observed components, where the trend is a random walk with drift, the cycle is an $\operatorname{AR}(p=q+1)$ stationary process, and the perturbations between both components are not correlated. Watson (1986) finds that in the unobserved components model, innovations have a lower impact on output fluctuations. However, this model is not significantly better than the ARIMA model. From this, he concludes that the sole specification of the model has consequences in the determination of cycles and hence, in economic policy decisions.

In a similar way, Clark (1987) applies a model of unobserved components with quarterly information for GDP and the industrial production of the United States from 1947 to 1985 . He retains the assumption of non-correlation between errors, but modifies the behavior of the trend, whose slope is now assumed to follow a random walk. At the same time, the cyclical component follows an AR (2) process for both series. From this specification, he concludes that the fluctuations in output depend almost in $50 \%$ of innovations in the cyclical component.

An alternative in the area of unobserved components is given by Kitagawa (1987). His model includes the presence of disturbances that do not follow a Gaussian distribution. According to the author, this allows one to deal with problems of outliers or non-linearity in the trend component. However, the 
component filter and the smoothing require large amounts of computational resources.

Stock and Watson (1988) summarize the main findings in the decomposition of output on the basis of ARIMA models or unobserved components. A distinct difference between both models is the importance of real innovations in the former and to a lesser degree in the latter. They argue that this is due to the presence of a stochastic trend and the hereby derived specification. On the one hand, the perfect correlation in ARIMA models is originated because in them, both the trend and the cyclical component are subject to only one type of shock. In this case, the correlation tends to be negative and allows one to define the cycle as an adjustment process in economic growth caused by a real shock, although the opposite is difficult to justify. Whereas, the null correlation between the cycle and trend lead to a higher relevance of the cyclical component. In both cases, identification defines in a certain way the preponderance of the one or the other types of shocks; however, there remain obstacles in the identification of the real source of the shock. On the other hand, the authors conclude that the assumption of the existence of a stochastic trend in the main macroeconomic series is valid and resembles the behavior of the United States data. Additionally, they conclude that in general, the permanent component has a higher impact on the economic fluctuations of that country.

In contrast, Cochrane (1988) puts in discussion the presence of a unit root in the GNP series of the United States. He concludes that in any case, its presence is minor and thus the shocks on the trend component are less important. On the other hand, Perron (1989) rejects the existence of a unit root for several of the series, including GNP, previously analyzed by Nelson and Plosser (1982). He posits as alternative hypothesis that the data generating process is stationary with a broken trend. The novelty in his proposal is the inclusion of two exogenous shocks that have a permanent effect on output. The first, due to the 1929 crisis, prompts a change in the trend level of GNP; the second, due to the oil crisis of 1973, brings about a change in the slope of the trend, which can be interpreted as the growth rate of potential GNP. The author concludes that the economic fluctuations are stationary around a broken deterministic trend. In consequence, changes in transitory behavior have a higher weight on business cycles.

The multivariate model of Blanchard and Quah (1989) presents a variant to the ARIMA and unobserved components models. They suggest a structural VAR model for quarterly output and unemployment in the United States from 1950 to 1987 . They solve the identification problem of univariate models by assuming that shocks of unemployment or demand do not have a permanent impact on output. On that basis, the authors find that demand shocks are relevant in the short and medium term, whereas supply shocks have a permanent impact on output and accumulate over time.

Another multivariate model is proposed by King et al. (1991), who posit the existence of a common stochastic trend for output, consumption and investment. By means of a cointegration analysis, they manage to eliminate that trend and to estimate the cyclical component of output. The authors find that more than $60 \%$ of real fluctuations is due to productivity shocks, although this share decreases to less than half if nominal variables are included. Hence, output fluctuations cannot be explained exclusively by real shocks. 
An important feature of the previously described models is that they assume linearity in the series and symmetry in the disturbances. However, the empirical evidence shows that negative shocks have a short duration and have a more profound impact on the output level. Friedman (1964) called this empirical peculiarity the "plucking" effect. The length of a recession is correlated to the length of the subsequent expansion, but not the opposite; that is, there is an asymmetry between positive and negative shocks. Besides, the drop of output varies in intensity, but always returns to the potential level. Friedman (1993) analyzes the output of the United States from 1975 to 1990 and finds evidence in favor of the "plucking" effect.

In a similar way, Neftci (1984) finds that in unemployment cycles in the United States, the transition from a recession to an expansion takes place without drastic changes; that is, there are asymmetries in the unemployment cycles. This effect is known in the business cycle literature as "duration dependence". A positive dependence on duration would indicate that expansions or recessions are more likely to end when they mature over time. Sichel (1991), Diebold and Rudebusch (1990), and Diebold et al. (1993) find evidence in favor of duration dependence in the GNP series of the United States, Great Britain and France. However, in all cases the dependence is asymmetrical, that is, it occurs only in recessions or in expansions. Sichel (1993) finds asymmetry in the depth of the unemployment cycle, industrial production and United States' GNP. That is, during recessions, output drops below trend more than it rises during expansions.

Taking into consideration the evidence of non-linearity of the series, Hamilton (1989) proposes a non-linear model with regime changes. In that model there are two regimes, one of positive output growth and one of negative growth. According to the author, the output in differences depends not only on its lags, but there is also a discrete change in the mean that generates a transition between positive and negative growth regimes. The change in the mean is caused by an unobserved exogenous variable that follows a first-order Markov process. One of the advantages of the model is the estimation of regime changes from data in the series. Additionally, it is possible to estimate the probabilities of being in a given regime, for example, a recession. Hamilton (1989) employs an AR (4) specification in order to model the quarterly growth rate of US GNP from 1950 to 1985 . He finds a recurrence in the regime changes. The transition from expansion to recession is associated with a drop of $3 \%$ of real output and a similar drop in the permanent component; that is, permanent shocks dominate output fluctuations. Later, Krolzig (1997) carries out a characterization of the different variables of the Markovswitching model, with changes in the mean, variance and/or intercept. Additionally, he generalizes Hamilton's proposal to a multivariate analysis. Whereas, Goodwin (1993) applies the Hamilton model to 8 countries of OECD without finding significant gains in comparison to other linear models, although the symmetry hypothesis is rejected for the majority of the countries.

Other alternative proposals of non-linear models are the "Exponential Autoregressive" model (EAR) of Haggan and Ozaki (1981), the "Threshold Autoregressive" model (TAR) of Tsay (1989) and the "Smooth Transition Autoregressive" model (STAR) of Teräsvirta (1994), which can be considered to contain the previous two. 
This latter model considers the existence of two regimes and the change between them follows a transition function that can be modeled with a logistic or exponential distribution. This function depends on an observable transition variable and is increasing when approaching or surpassing a given threshold. From this starting point, a smoothed transition between regimes is generated. It is important to note that a previous step to the application of the model is to reject the non-linearity of the series, the alternative hypothesis being the logistic or exponential STAR model. Following these criteria, Teräsvirta and Anderson (1992) estimate the STAR model for the quarterly production index or 13 OECD economies. They find that the model is adequate in describing the non-linearities and asymmetries of the series.

In the area of multivariate models, Kuttner (1994) exploits the theoretical relation between output and inflation through the Phillips curve. He proposes a bivariate decomposition of unobserved components. Output is decomposed in trend and cycle in a similar way as in the Clark (1987) model, whereas inflation depends on past inflation and the deviation of output from its potential level. One of the advantages of this method resides in the possibility of incorporating in a simple way the theoretical relations between output and other economic variables. In his analysis, Kuttner (1994) finds that the coefficient that measures the sensitivity between the output gap and inflation is significant; that is, the Phillips curve is relevant in the analysis of both series. Besides, the permanent shocks have larger impacts on output, in comparison to a univariate model.

Taking into consideration the evidence of asymmetry in cycles, Kim and Nelson (1999a) specify a model of unobserved components denominated "plucking". In this model, the cyclical component follows an AR (2) process, with disturbances composed by a mix of two types of shocks: symmetrical and asymmetrical. The existence of the latter depends on the probability of occurrence of a recession; that is, in normal times only the symmetrical shock remains. The trend component is modeled as a random walk that suffers two types of disturbances: one on the level and another that affects the trend rate of growth. The authors follow Friedman (1993) in specifying the output trend as a "ceiling" trend; according to this, output reaches a maximum level in normal times and deviates below trend during recessions. The model is applied to quarterly GNP series and the unemployment rate in the United States for the 1951:1995 period, generating negative cycles during the recession periods. In consequence, in normal times output is driven by permanent shocks; real business cycle models are thus ideal in explaining the behavior of output. However, in times of recession the transitory shocks predominate, and monetary and other demand-oriented models are pertinent. A later application of the "plucking" model is carried out by Mills and Wang (2002) for the G7 countries.

There are additionally other methods of decomposition in trend and cycle using statistical filters. One of the most commonly used is the filter proposed by Hodrick and Prescott (1997), where the trend is extracted through a least squares criterion. It is assumed that there is symmetry in the cycles and that the trend follows a smoothed behavior. This filter can be catalogued as "high-pass", for it eliminates the low-frequency cycles. Other methods are those proposed by Baxter and King (1990) and by Christiano and Fitzgerald (2003), which are filters of the type "band- 
pass" that eliminate the high and low frequency components, allowing the extraction of smoothed cycles. One of the advantages of these filters is their ease of application, since they do not assume a given behavior of the series. However, they present some disadvantages. In the first place, "high-pass" filters such as Hodrick and Prescott (1997) can generate spurious cycles (Harvey and Jaeger 1993). For their part, "band-pass" filters do not completely isolate the cycle, which could be confused with the trend in differences (Murray 2003). A generalization of the previous filters are the "Butterworth" filters proposed by Harvey and Trimbur (2003), from which data-consistent high-pass or band-pass filters can be obtained. However, despite the improvements in filter specification, the problem of symmetry in the cycles and a lack of theoretical fundamentals in their construction remains.

Regarding the assessment of these methods, Canova (1998) carries out a balance on the application of different filters to quarterly macroeconomic series such as output, consumption, investment, and productivity in the United States for the 1953-1986 period. His purpose is to contrast empirical regularities with the proposed economic theory, regardless of the utilized filter. Among the main stylized facts he finds with a certain robustness are a high correlation between the output cycles and investment, and a lower volatility of consumption with respect to output, although with differences in magnitude given the used filter. In contrast, the procyclicality of productivity depends on the utilized filters. Other stylized facts of modern macroeconomics are: the negative correlation between output cycles and unemployment, and the negative, short term relation between inflation and unemployment cycles. Starting from this stylized facts, several authors build models of multivariate unobserved components in order to obtain in a joint manner the cycles and trends of different series. For example, Apel and Jansson (1998) estimate the output and unemployment cycle in the United States, Canada and the United Kingdom by using Okun's law. Laubach (2001) estimates NAIRU and the employment cycles for the G7 countries using the Phillips curve. And Doménech and Gómez (2006) include an investment behavior equation that depends on the output cycle, in addition to Okun's Law and the Phillips Curve.

Regarding the analysis of ARIMA and unobserved components models and the differences between them, Morley et al. (2003) find that both models are theoretically equivalent. However, their results differ because the unobserved components model requires, for purposes of specification, to impose restrictions of zero correlation between the innovations in trend and cycle. By evaluating each model separately, they find that the unrestricted ARIMA model has a better performance in terms of the likelihood function; besides, the analysis of data rejects the possibility of zero correlation, whereas an unobserved components model that admits correlation leads to the same results than an equivalent ARIMA model. In consequence, what distinguishes one model from another is the degree of correlation in the disturbances. A strong, negative correlation leads to the ARIMA model of Beveridge and Nelson (1981), whereas the null correlation leads to the unobserved components model of Watson (1986). They estimate the trend and cycle of the quarterly output in the United States for the 1947-1998 period by following the ARIMA $(2,1,2)$ specification, which results in short duration cycles and reinforces the idea of the preponderance of real shocks in the business cycle, although the 
cycles thus obtained are symmetrical. Later, Oh and Zivot (2006) extend the proposal of Morley et al. (2003) applied to the Clark (1987) model, which in a reduced form is an ARIMA (2,2,3), and reject the idea of a trend with double drift. Similarly, Basistha (2007) extends the model to a multivariate analysis.

In the domestic literature, there is the work of Cabredo and Valdivia (1999), who apply diverse methods for estimating Peruvian potential output from 1950 to 1997 starting from an aggregate production function, the Hodrick and Prescott (1997) filter, and a structural VAR. On the other hand, Miller (2003) distinguishes among methods of the structural and non-structural kind. For the former, he employs the Hodrick and Prescott (1997) filter, a method of segmented trend, a non-parametric smoothing method, the Baxter and King (1999) filter, and the Beveridge and Nelson (1981) decomposition; whereas, for the latter, he employs the production function and a structural VAR. Her estimations are based on the yearly Peruvian GDP series from 1951 to 2001, and she finds that all methods have the ability to identify the cycles in the economy, although they differ in the magnitude of the cycle and tend to underestimate the recessionary cycles during the big recessions of the 1980s.

In analogous fashion, Seminario et al. (2007) use a set of methods such as the Hodrick and Prescott (1997) filter, the Baxter and King (1999) filter, the peaks method $^{3}$, the method of Marfán and Artiagoitia (1989) and a sectoral method in order to obtain potential output from 1950 to 2007. On the other hand, Castillo et al. (2007) use the Baxter and King (1999) filter in order to obtain the cyclical component of output within the analysis of the stylized facts of the Peruvian economy.

From another viewpoint, Rodríguez (2010a) uses three non-linear methods in order to decompose the cyclical element from a series. The STAR model by Teräsvirta (1994), the "Markov switching" of Hamilton (1989) and the "plucking" model of Kim and Nelson (1999a) are applied to the analysis of the quarterly series of Peruvian GDP from 1980 to 2005. The three models reject the linearity of the series. The MSIAH (3) model, which is based on a Markov switching model with three regimes and an AR (4) from the output in differences, generates recession periods that are more in line with the empirical dating of recessions ${ }^{4}$. However, periods following 1990 and characterized as recessions $(1998,2011)$ are not captured by any model. The explanation proposed by the author is based on the strong contractions or expansions of the Peruvian economy, which makes the correct identification of cycles more difficult.

In Rodríguez (2010b), the estimation of the cyclical component of GDP is supported by the neo-Keynesian theory. Keeping the specification of Basistha and Nelson (2007), one assumes the existence of a Phillips curve that depends on the expected inflation, past inflation and the output cycle. A bivariate model of unobserved components allows one to extract the output cycle for the period 1980-2005. In a similar way, the relevance of the Phillips curve is tested.

\footnotetext{
3 Methodology that was proposed to NBER in order to identify the peaks of a series. The authors follow the explanation provided by Ochoa and Lladó (2003) with respect to this method.

4 A recession is defined as a period which registers falls in real GDP for more than two consecutive quarters.
} 
Additionally, in comparison to other models, significant differences are obtained with the exception of the Clark (1987) model.

While keeping the multivariate specification, Rodríguez (2010c), following Dómenech and Gómez (2006), uses an unobserved components model in order to capture the relations between output trend and cycle, the Phillips curve, Okun's Law and an investment behavior function. Using this model, he extracts the cyclical component of output, the underlying inflation rate and the structural or NAIRU unemployment rate from 1980 to 2007.

Recently, Wada and Perron (2006) and Perron and Wada (2009) have suggested a new model of decomposition of trend and cycle, which admits structural changes in the trend and asymmetry in the cyclical component. They use a non-linear model of unobserved components, whose disturbances consist of a mixture of normal distributions both for the cyclical component and the trend component. This specification allows one to capture swift changes in an endogenous way, at the same time that it overcomes the discussion between ARIMA and unobserved component models, since it does not impose restrictions on the correlation between cycle and trend disturbances. After analyzing quarterly GDP of the United States for the 1947-1998 period, the authors find that, with the exception of changes in the slope, the trend of output is deterministic. On the other hand, the cyclical component presents asymmetries and is relevant in economic fluctuations. Besides, in comparison to other methods (Hodrick and Prescot 1997; Baxter and King 1999; Beveridge and Nelson 1981; unobserved components), the cycles of boom and recession are better adjusted to the NBER timeline.

The Wada and Perron (2006) and Perron and Wada (2009) methods present certain advantages with respect to earlier models, especially when dealing with series that have undergone structural changes. In the first place, the method features a great degree of flexibility to capture the different changes in the behavior of the series. A structural change can be modeled as an abrupt shock to trend that takes place with a low probability, whereas smaller shocks occur with a higher probability, giving shape to a stochastic trend. In the same way, low and high impact shocks on the cycle can reflect short term policies that are very expansionary in situations of crisis, but less so in normal times.

Secondly, this method overcomes the identification problem that is present in both ARIMA and unobserved components models, for each disturbance consists of a mixture of two normal distributions, which are not correlated with other disturbances (although, as a whole, the mix can be correlated with another one). This specification is an alternative to that proposed by Morley et al. (2003), with the advantage that it admits asymmetries in the output cycles.

Thirdly, the method is capable of capturing the non-linearities of the series and identifying the probabilities related to being in a high or low variance regime, without the need of assuming that the transition from one regime to another follows a Markov process. The latter can constitute a strong assumption when dealing with emerging economies, which have undergone large structural changes which are unlikely to be repeated. For example, in the Peruvian case the estimations of Rodríguez (2010a) based on the Hamilton (1989) model and the "plucking" model 
of Kim and Nelson (1999a) do not identify recessionary periods after 1990. One plausible explanation to the latter is that these models assume the existence of a Markov process, which is not very useful for Peruvian GDP that shows a very different behavior in the periods before and after $1990 .^{5}$

Fourthly, the specification to be used allows the identification of break points in an endogenous fashion, and finally, it is superior to statistical high-pass or band-pass filters, as it does not impose smoothing restrictions to the series.

In view of these advantages, it is convenient to apply the Wada and Perron (2006) and Perron and Wada (2009) method to decompose Peruvian GDP into trend and cycle. First, we attempt to capture the effect of non-linearities and asymmetries present in output that have been documented by Rodríguez (2010a). And, second, to identify the structural change that took place in the early 1990s, where important institutional reforms were enacted that, according to Castillo et al. (2007), made possible a more stable growth of the economy. It is important to highlight that previous estimations could not associate that structural break with a behavior of the trend or a long-term component of output. Finally, we expect that this methodology will allow a better identification of recessive cycles, especially in periods after 1990, which is why the obtained cycles will be compared with those produced by other methods and with the timeline of recessions that is usually employed.

\section{Methodology}

We aim to extract the trend and cycle of Peruvian GDP by using the method proposed by Wada and Perron (2006). In consequence, we built an empirical model of non-linear output decomposition into non-observable components, according to the following specification:

$$
\begin{gathered}
y_{t}=\tau_{t}+c_{t}+\omega_{t}, \\
\tau_{t}=\tau_{t-1}+\beta_{t}+\eta_{t}, \\
\beta_{t}=\beta_{t-1}+v_{t}, \\
c_{t}=\phi_{1} c_{t-1}+\phi_{2} c_{t-2}+\epsilon_{t},
\end{gathered}
$$

where $y_{t}$ is the observable series, $\tau_{t}$ is the trend, $c_{t}$ is the cyclical component, $\beta_{t}$ is the variable that allows changes in the trend slope and $\omega_{t}, \eta_{t}, v_{t}, \epsilon_{t}$ are the disturbance terms. The model is non-linear due to the behavior of the disturbance terms. If they are represented by $u_{t}$, then they have the following distribution:

$$
u_{t}=\lambda_{t} \gamma_{1 t}+\left(1-\lambda_{t}\right) \gamma_{2 t}
$$

\footnotetext{
5 In the early 1990s, a large structural adjustment was applied to the economy and institutional reforms were started which affected the dynamic of Peruvian GDP. An extensive analysis is provided in Castillo et al. (2007). In the same direction, but focused on the American economy, is the estimation of Kim and Nelson (1999), who apply the model of Hamilton (1989) extending the sample until the late 1990s, and find that the periods of recession are not correctly identified. This loss of efficacy of the model is due to a structural change in the American economy, whose potential rate of growth decreased in the late 1980s.
} 
where $\gamma_{i t} \sim$ i.i.d. $N\left(0, \sigma_{i}^{2}\right)$ and $\lambda_{t} \sim$ i.i.d. Bernoulli $(\alpha) .{ }^{6}$ The error in $t$ behaves as a $N\left(0, \sigma_{1}^{2}\right)$ with probability $\alpha$ and as $N\left(0, \sigma_{2}^{2}\right)$ with probability $(1-\alpha)$. This specification allows us to capture the non-linearities of the path of the output. For example, if $\alpha$ takes a value close to 1 and $\sigma_{2}^{2}$ is much higher than $\sigma_{1}^{2}$, then there would be, most of the time, periods of low variance or "normal", whereas on an exceptional basis, large shocks that alter the level of the series would take place. The latter would be "atypical" periods that could be associated with periods of recession or structural changes.

Several feasible scenarios can be considered. In one of them, the disturbance $\omega_{t}$ would be expected to be very small or close to zero in "normal periods" and of a larger magnitude only in the case of atypical situations, where the output level is affected but not the potential level, for example, during natural disasters. In another scenario, the disturbance $\eta_{t}$ generates a stochastic trend or, on the opposite, if $\sigma_{1}^{2}=0$, a deterministic trend with occasional changes in the level. With respect to the disturbance $v_{t}$, one could expect it to be small most of the time and to take a larger magnitude only in atypical periods. Finally, the disturbance $\epsilon_{t}$ can have different variances depending on whether the economy is in a period of moderate growth or high volatility. Each of these scenarios is not independent of the other and they can combine indistinctly, thereby affecting the evolution of economic cycles.

Wada and Perron (2006) focus on the importance of changes in the level and slope of the trend, and as such, their model only allows the disturbances $\eta_{t}$ and $v_{t}$ to be composed by a mixture of normals. In contrast, Perron and Wada (2009) allow a change in the slope of the trend and asymmetrical cycles thanks to the specification of $v_{t}$ and $\epsilon_{t}$ as mixtures of normals.

In the last 30 years, Peruvian GDP has undergone important changes, ranging from deep losses and periods of fast growth, to drastic changes in the production structure. This supports the hypothesis that the aggregate output has a non-linear behavior that includes discrete changes in its trend or its potential growth rate. These changes can be originated by positive or negative disturbances that take place with a small probability, but have a large impact on the dynamic of output in the long term, for example, periods of economic reforms, internal conflict or institutional reform. On the other hand, during recessions, the magnitude of the variation of output tends to be larger than during expansion periods, but the duration of this high variance period is relatively short. This can be explained by an asymmetrical cyclical component where disturbances of large magnitude, which take place infrequently, have a serious impact on output in the short term, for example, in the event of adverse external shocks and monetary or fiscal policies.

Regarding empirical studies, Rodríguez (2010a) finds evidence in favor of the presence of non-linearities in Peruvian GDP and of asymmetries in its cyclical component. In consequence, one could establish the existence of mixtures of normals in the trend level, in its growth rate, and in the cyclical component of

\footnotetext{
${ }^{6}$ In a Bernoulli distribution $(\alpha)$ the random variable takes the value of 1 if the event occurs with success and of 0 if it fails. Thus, the probability of success is $\alpha$ and the probability of failure is $1-\alpha$.
} 
output. One could even allow the presence of a mixture of normals in the measurement equation that would capture the effect of atypical output changes or outliers. For example, natural disasters that drastically affect the level of Peruvian output, and take place irregularly, would be mistakenly estimated within the cyclical component. However, according to Wada and Perron (2006), the inclusion of all disturbances as mixtures of normals implies an unstable estimation algorithm.

Given the previous discussion, we considered to restrict the number of scenarios under consideration. Wada and Perron (2006) utilize up to two disturbances with mixtures of normals. This restriction in the number of mixtures is a consequence of a problem of identification. For example, a country that does not undergo structural changes during the period of analysis would have a very stable trend and periods of high and low variance would not be justified. The imposition of both regimes could generate extreme values in the variances and their probabilities of occurrence. In the case of Peru, the opposite is true: the fluctuations of output are very irregular and one could even estimate a model with three mixtures of variables.

We take on all estimation possibilities starting with the simpler models that admit only one mixture of normals. We then continue with models that contemplate combinations of two mixtures of normals, and explore the possibility of a model that admits up to three mixtures of normals, in order to find the best specification for the Peruvian economy. As such, the following estimations are laid out:

- UC-C: a model with a mixture in the cyclical component $\left(\epsilon_{t}\right)$.

- UC-N: a model with a mixture in the disturbances of the trend level $\left(\eta_{t}\right)$.

- UC-P: a model with a mixture in the disturbances of the trend slope $\left(v_{t}\right)$.

- UC-CN: a model with mixtures in the disturbances of the cyclical component and the trend level $\left(\epsilon_{t}, \eta_{t}\right)$.

- UC-CP: a model with mixtures in the disturbances of the cyclical component and the trend slope $\left(\epsilon_{t}, v_{t}\right)$.

- UC-NP: a model with mixtures in the disturbances of the trend level and trend slope $\left(\eta_{t}, v_{t}\right)$.

- UC CNP: a model with mixtures in the disturbances of the cyclical component, the trend level and the trend slope $\left(\epsilon_{t}, \eta_{t}, v_{t},\right)$.

\subsection{Estimation method}

The estimation of the non-observable components will be carried out by a statespace representation. For notation purposes, it is important to have in mind that $\eta_{t}, v_{t}$ and $\epsilon_{t}$ are the disturbances on the trend level, the trend slope and the cyclical component, respectively. Some or all of which consist of a mixture of normal distributions, depending on the model; whereas the remaining disturbances follow a normal distribution. Moreover, $\alpha_{i}$ is the probability that the disturbance $i=\eta_{t}, \epsilon_{t}, v_{t}$ is within a low variance regime, $\sigma_{i 1}^{2}$, while $\left(1-\alpha_{i}\right)$ is the probability that it is within 
the high variance regime $\sigma_{i 2}^{2}$. The estimation method starts from the following statespace representation:

$$
\begin{aligned}
& y_{t}=H x_{t}+\omega_{t} \\
& x_{t}=F x_{t-1}+G u_{t},
\end{aligned}
$$

where

$$
H^{\prime}=\left[\begin{array}{l}
1 \\
1 \\
0 \\
0
\end{array}\right], \quad x_{t}=\left[\begin{array}{c}
\tau_{t} \\
c_{t} \\
c_{t-1} \\
\beta_{t}
\end{array}\right], \quad F=\left[\begin{array}{cccc}
1 & 0 & 0 & 1 \\
0 & \phi_{1} & \phi_{2} & 0 \\
0 & 1 & 0 & 0 \\
0 & 0 & 0 & 1
\end{array}\right], \quad G=I, \quad u_{t}=\left[\begin{array}{c}
\eta_{t} \\
\epsilon_{t} \\
0 \\
v_{t}
\end{array}\right]
$$

In contrast to conventional models, the disturbance vector $u_{t}$ does not follow a normal distribution. However, it is feasible to assign a normal distribution with possible states to the state-space representation. The variance and covariance matrix of $u_{t}$ takes $M$ possible states that are generated as a result of the combination of values taken by the Bernoulli random variables. For example, in a model with a mixture of normals there are only two possible states that are associated with periods of low and high variance, whereas in a model with two mixtures of normals, four possible states will exist associated with combinations of high and low variance for each disturbance. In consequence, there are $2^{m}$ possible states, where $m$ is the number of disturbances with mixtures of normals. The $Q$ variance and covariance matrix for a model with only one mixture of normals such as $\mathrm{UC}-\mathrm{C}^{7}$ is given by:

$$
Q=\left\{\left[\begin{array}{cccc}
\sigma_{\eta}^{2} & 0 & 0 & 0 \\
0 & \sigma_{\epsilon_{1}}^{2} & 0 & 0 \\
0 & 0 & 0 & 0 \\
0 & 0 & 0 & \sigma_{v}^{2}
\end{array}\right]\left[\begin{array}{cccc}
\sigma_{\eta}^{2} & 0 & 0 & 0 \\
0 & \sigma_{\epsilon_{2}}^{2} & 0 & 0 \\
0 & 0 & 0 & 0 \\
0 & 0 & 0 & \sigma_{v}^{2}
\end{array}\right]\right\}
$$

where each state or regime occurs with probabilities $\alpha_{1}$ and $\left(1-\alpha_{1}\right)$. The $Q$ matrix for a model with two mixtures of variables like UC-CN would be:

$$
Q=\left\{\left[\begin{array}{cccc}
\sigma_{\eta_{1}}^{2} & 0 & 0 & 0 \\
0 & \sigma_{\epsilon_{1}}^{2} & 0 & 0 \\
0 & 0 & 0 & 0 \\
0 & 0 & 0 & \sigma_{v}^{2}
\end{array}\right]\left[\begin{array}{cccc}
\sigma_{\eta_{2}}^{2} & 0 & 0 & 0 \\
0 & \sigma_{\epsilon_{1}}^{2} & 0 & 0 \\
0 & 0 & 0 & 0 \\
0 & 0 & 0 & \sigma_{v}^{2}
\end{array}\right]\left[\begin{array}{cccc}
\sigma_{\eta_{1}}^{2} & 0 & 0 & 0 \\
0 & \sigma_{\epsilon_{2}}^{2} & 0 & 0 \\
0 & 0 & 0 & 0 \\
0 & 0 & 0 & \sigma_{v}^{2}
\end{array}\right]\left[\begin{array}{cccc}
\sigma_{\eta_{2}}^{2} & 0 & 0 & 0 \\
0 & \sigma_{\epsilon_{2}}^{2} & 0 & 0 \\
0 & 0 & 0 & 0 \\
0 & 0 & 0 & \sigma_{v}^{2}
\end{array}\right]\right\},
$$

where each state occurs with probabilities $\alpha_{1} \alpha_{2}, \alpha_{1}\left(1-\alpha_{2}\right),\left(1-\alpha_{1}\right) \alpha_{2}$, and $(1-$ $\left.\alpha_{1}\right)\left(1-\alpha_{2}\right)$ respectively. Finally, the $Q$ variance and covariance matrix for a model with 3 mixtures of normals would be defined as:

\footnotetext{
7 The representation can be generalized for the other cases.
} 


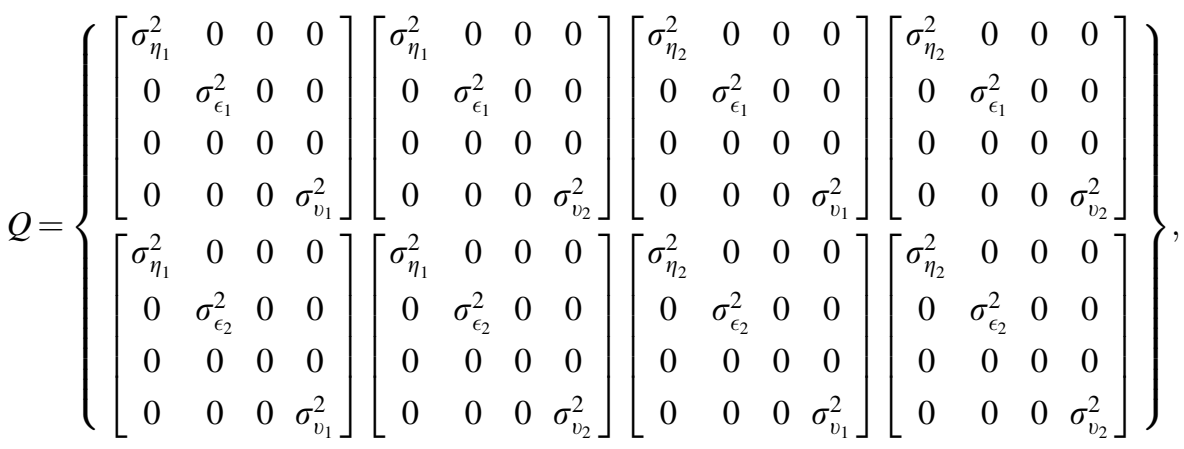

where each state occurs with probabilities $\alpha_{1} \alpha_{2} \alpha_{3}, \alpha_{1} \alpha_{2}\left(1-\alpha_{3}\right), \alpha_{1}\left(1-\alpha_{2}\right) \alpha_{3}, \alpha_{1}(1-$ $\left.\alpha_{2}\right)\left(1-\alpha_{3}\right),\left(1-\alpha_{1}\right) \alpha_{2} \alpha_{3},\left(1-\alpha_{1}\right) \alpha_{2}\left(1-\alpha_{3}\right),\left(1-\alpha_{1}\right)\left(1-\alpha_{2}\right) \alpha_{3}$ and $\left(1-\alpha_{1}\right)(1-$ $\left.\alpha_{2}\right)\left(1-\alpha_{3}\right)$ respectively.

The estimation process starts with the application of the Kalman filter, which follows the same principles as the state-space model with normal disturbances laid out by Harvey (1989). Afterwards, the Hamilton filter is added according to the approach of Kim and Nelson (1999b). The Kalman filter considers the estimation of the expected value of the $x_{t}$ vector, conditional to the information available until period $t$. This new vector $x_{t \mid t}$ is called filtered estimator. In a second stage, we built an estimator conditional to all information available in the sample, vector $x_{t \mid T}$, which is called smoothed estimator and is obtained after utilizing a smoothing algorithm. This last vector is relevant for the study, for the aim is to carry out an inference of the nonobservable components $\left(\tau_{t}, c_{t}\right)$ from the basis of all information available. The steps of that estimation are described as follows.

Step 1: Kalman Filter We look for the best estimator of the state vector and its variance and covariance matrix. To this end, we know that in a model with normal disturbances, the best linear estimator of the state vector is the linear minimum mean square error estimator (MMSE), $x_{t \mid t-1}$, which is forecast on the basis of all information available up to the period $t-1$. For its part, $P_{t \mid t-1}$ is the mean square error (MSE) or the variance of the forecast error of $x_{t \mid t-1}$. Formally:

$$
\begin{gathered}
x_{t \mid t-1}=E\left[x_{t} \mid Y_{t-1}\right], \\
P_{t \mid t-1}=E\left[\left(x_{t}-x_{t \mid t-1}\right)\left(x_{t}-x_{t \mid t-1}\right)^{\prime} \mid Y_{t-1}\right] .
\end{gathered}
$$

However, there are high and low variance regimes that are represented in the different states taken by the $Q$ variance and covariance matrix. Hence, if we denominate $S_{t}$ as the variable that indicates the regime (low or high volatility) in which the state vector is located in time $t$, we obtain:

$$
\begin{gathered}
x_{t \mid t-1}^{i j}=E\left[x_{t} \mid Y_{t-1}, S_{t-1}=i, S_{t}=j\right] \quad i, j=1, \ldots, M \\
P_{t \mid t-1}^{i j}=E\left[\left(x_{t}-x_{t \mid t-1}\right)\left(x_{t}-x_{t \mid t-1}\right)^{\prime} \mid Y_{t-1}, S_{t-1}=i, S_{t}=j\right],
\end{gathered}
$$

where the superindices $(i j)$ show that the value of the variable is conditional to the fact of being in state $i$ in the period $t-1$ and in state $j$ in the period $t$, and $M$ is the 
number of possible states. This representation is similar to the Markov Switching model by Hamilton (1989). The fundamental difference is that the probability of being in the regime $S_{t}$ does not depend on the past probability of being in the regime $S_{t-1}$, which only affects the state variables. In a simple example, one could assert that if in $t-1$ the probability of being in a high volatility period was very low, this does not imply that in $t$ the volatile period takes place. Conditional to $S_{t-1}=i$ and $S_{t}=j$, the following algorithm of the Kalman filter is obtained:

$$
\begin{gathered}
x_{t \mid t-1}^{i j}=F x_{t-1 \mid t-1}^{i}, \\
P_{t \mid t-1}^{i j}=F P_{t-1 \mid t-1}^{i} F^{\prime}+G Q^{j} G^{\prime}, \\
v_{t \mid t-1}^{i j}=y_{t}-H x_{t \mid t-1}^{i j}, \\
f_{t \mid t-1}^{i j}=H P_{t \mid t-1}^{i j} H^{\prime}+R, \\
x_{t \mid t}^{i j}=x_{t \mid t-1}^{i j}+P_{t \mid t-1}^{i j} H^{\prime}\left[f_{t \mid t-1}^{i j}\right]^{-1} v_{t \mid t-1}^{i j}, \\
P_{t \mid t}^{i j}=\left(I-P_{t \mid t-1}^{i j} H^{\prime}\left[f_{t \mid t-1}^{i j}\right]^{-1} H\right) P_{t \mid t-1}^{i j},
\end{gathered}
$$

where $x_{t-1 \mid t-1}^{i}$ is the value that $x_{t-1}$ is inferred to take on the basis of information available up to $t-1$ and conditional to being in the state $S_{t-1}=i ; x_{t \mid t-1}^{i j}$ is the inference of $x_{t}$ until $t-1$ given $S_{t-1}=i$ and $S_{t}=j$. On the other hand, $P_{t \mid t-1}^{i j}$ is the mean square error of $x_{t \mid t-1}^{i j}$ conditional to $S_{t-1}=i$ and $S_{t}=j, v_{t \mid t-1}^{i j}$ is the forecast error of $y_{t}$ based on the information available until $t-1$ and conditional to $S_{t-1}=i$ and $S_{t}=j ; f_{t \mid t-1}^{i j}$ is the conditional variance of the forecast error $v_{t \mid t-1}^{i j}$. Finally, $x_{t \mid t}^{i j}$ and $P_{t \mid t}^{i j}$ are the values that the variables are inferred to take after the updating process of the Kalman filter takes place.

Step 2: Hamilton Filter We aim to infer the probability associated with the state vector estimator and its variance and covariance matrix.

At the start of the iteration process, for the period $t$, given $S_{t-1}=i$ and $S_{t}=j$ and taking into consideration that both variables are independent ${ }^{8}$, we can calculate the joint probabilities of being in a given regime $S_{t}$ and to originate from another $S_{t-1}$ regime, conditional to the past realizations $Y_{t-1}$ in the following way:

$$
\begin{aligned}
& \operatorname{Pr}\left(S_{t-1}=i, S_{t}=j \mid Y_{t-1}\right)=\operatorname{Pr}\left(S_{t}=j \mid S_{t-1}=i\right) \operatorname{Pr}\left(S_{t-1}=i \mid Y_{t-1}\right), \\
& \operatorname{Pr}\left(S_{t-1}=i, S_{t}=j \mid Y_{t-1}\right)=\operatorname{Pr}\left(S_{t}=j\right) \operatorname{Pr}\left(S_{t-1}=i \mid Y_{t-1}\right) .
\end{aligned}
$$

Besides, we have the joint density function of $y_{t}, S_{t-1}$ and $S_{t}$ :

$$
p\left(y_{t}, S_{t-1}=i, S_{t}=j \mid Y_{t-1}\right)=p\left(y_{t} \mid S_{t-1}=i, S_{t}=j, Y_{t-1}\right) \operatorname{Pr}\left(S_{t-1}=i, S_{t}=j \mid Y_{t-1}\right),
$$

where the marginal density function of $y_{t}$ is given by:

\footnotetext{
${ }^{8}$ In contrast with the model of Hamilton (1989), where $\operatorname{Pr}\left(S_{t-1}=i, S_{t}=j\right)$ is the probability of transition.
} 


$$
p\left(y_{t} \mid Y_{t-1}\right)=\sum_{j=1}^{M} \sum_{i=1}^{M} p\left(y_{t} \mid S_{t-1}, S_{t}, Y_{t-1}\right) \operatorname{Pr}\left(S_{t-1}=i, S_{t}=j \mid Y_{t-1}\right),
$$

and the conditional density function $p\left(y_{t} \mid S_{t-1}, S_{t}, Y_{t-1}\right)$ is calculated on the basis of the forecast error and its variance, which are obtained from the equations of the Kalman filter:

$$
p\left(y_{t} \mid S_{t-1}, S_{t}, Y_{t-1}\right)=\frac{1}{\sqrt{2 \pi}}\left|f_{t \mid t-1}^{i j}\right|^{-1 / 2} \exp \left\{-\frac{v_{t \mid t-1}^{i j^{\prime}}\left(f_{t \mid t-1}^{i j}\right)^{-1} v_{t \mid t-1}^{i j}}{2}\right\} .
$$

When $Y_{t}$ is observed in period $t$, it is possible to update the probability $\operatorname{Pr}\left(S_{t-1}=\right.$ $\left.i, S_{t}=j \mid Y_{t-1}\right)$ as follows:

$$
\begin{gathered}
\operatorname{Pr}\left(S_{t}=j\right) \operatorname{Pr}\left(S_{t-1}=i \mid Y_{t}\right)=\operatorname{Pr}\left(S_{t-1}=i, S_{t}=j \mid y_{t}, Y_{t-1}\right)=\frac{p\left(y_{t}, S_{t}, S_{t-1} \mid Y_{t-1}\right)}{p\left(y_{t} \mid Y_{t-1}\right)} \\
\operatorname{Pr}\left(S_{t-1}=i, S_{t}=j \mid Y_{t}\right)=\frac{p\left(y_{t} \mid S_{t}, S_{t-1}, Y_{t-1}\right) \operatorname{Pr}\left(\mathrm{S}_{\mathrm{t}-1}=\mathrm{i}, \mathrm{S}_{\mathrm{t}}=\mathrm{j} \mid \mathrm{Y}_{\mathrm{t}-1}\right)}{p\left(y_{t} \mid Y_{t-1}\right)}
\end{gathered}
$$

and to obtain the probability associated with each regime $S_{t}$ conditional to the information available until period $t$ :

$$
\operatorname{Pr}\left(S_{t}=j, Y_{t}\right)=\sum_{i=1}^{M} \operatorname{Pr}\left(S_{t-1}=i, S_{t}=j \mid Y_{t}\right) .
$$

Finally, being $Y_{T}=\left(y_{1}, y_{2}, \ldots, y_{t}\right)$ the vector of data available in period $t$, the likelihood function is maximized:

$$
\ln \left[p\left(Y_{T}\right)\right]=\ln \left[\sum_{t=1}^{T} p\left(y_{t} \mid Y_{t-1}\right)\right]
$$

Step 3: Collapsing There is a dimensionality problem if one aims to estimate the previously described algorithm, since it requires the estimation of $4^{t}$ estimators and their respective mean squared errors. In order to render the Kalman filter operable, a process of "collapsing" is employed, which re-approximates the estimators $x_{t \mid t}^{i j}$ and $P_{t \mid t}^{i j}$ in each period $t$ to $x_{t \mid t}^{j}$ and $P_{t \mid t}^{j}$. Following Wada and Perron (2006), we adopt the method of Harrison and Stevens (1976), where:

$$
\begin{gathered}
x_{t \mid t}^{j}=\frac{\sum_{i=1}^{M} \operatorname{Pr}\left(S_{t-1}=i, S_{t}=j \mid Y_{t}\right) x_{t \mid t}^{i j}}{\operatorname{Pr}\left(S_{t}=j \mid Y_{t}\right)}, \\
P_{t \mid t}^{j}=\frac{\sum_{i=1}^{M} \operatorname{Pr}\left(S_{t-1}=i, S_{t}=j \mid Y_{t}\right)\left\{P_{t \mid t}^{i j}+\left(x_{t \mid t}^{i}-x_{t \mid t}^{i j}\right)\left(x_{t \mid t}^{i}-x_{t \mid t}^{i j}\right)^{\prime}\right\}}{\operatorname{Pr}\left(S_{t}=j \mid Y_{t}\right)} .
\end{gathered}
$$

The first equation indicates that in each period $M$ vectors of state $x_{t \mid t}^{i j}$ are generated, and each of them is weighted by the probabilities of coming from a given regime 
$S_{t-1}$ and of being in another regime $S_{t}$. One proceeds in similar fashion for the $M$ variances $P_{t \mid t}^{i j}$ that are generated in each period. Since the state variable is conditional only to being in the regime $S_{t}=j$, the estimator filtered in each period $t$ is obtained as follows:

$$
x_{t \mid t}=\sum_{j=1}^{M} \operatorname{Pr}\left(S_{t}=j \mid Y_{t}\right) x_{t \mid t}^{j} .
$$

The collapsing allows one to reduce the possible states that the variables can take. For example, if one starts in $t=1$ there are $j$ possible states, in $t=2$ each of them generates $j$ additional possible states, and so on; in time, the dimension of states grows. With the proposed method, in each period $t$ there will only be $j$ possible states that are of interest for the analysis of cycles; that is, those linked to periods of high and low variance.

\subsection{Initial values}

The recursive method of the Kalman filter requires initial values for the state vector $x_{0 \mid 0}$ and for the variance of the forecast error $P_{0 \mid 0}$. These values are chosen after the proposal of Wada and Perron (2006). For example, in the case of the state vector, we have:

$$
x_{0 \mid 0}=\left[\tau_{0}, 0,0, \beta_{0}\right]^{\prime},
$$

where the initial trend value, $\tau_{0}$, is the first observation of GDP. The initial value of the slope, $\beta_{0}$, corresponds to the simple average of the growth rate of the first four quarters. ${ }^{9}$ Whereas, the initial values of the cycles, $c_{t}$ and $c_{t-1}$, are their steady state values. On the other hand, the initial values of the variance of the forecast error are given by:

$$
P_{0 \mid 0}=\left[\begin{array}{ccc}
1 \mathrm{e}+08 & 0 & 0 \\
0 & P & 0 \\
0 & 0 & 1 \mathrm{e}+08
\end{array}\right],
$$

where the submatrix $P$ is obtained from $\operatorname{vec}(P)=\left[I_{2}-F_{1} \otimes F_{1}\right]^{-1} \operatorname{vec}\left(Q_{1}\right)$, with

$$
F_{1}=\left[\begin{array}{cc}
\phi_{1} & \phi_{2} \\
1 & 0
\end{array}\right] \quad Q_{1}=\left[\begin{array}{cc}
\sigma_{1 \epsilon}^{2} & 0 \\
0 & \sigma_{2 \epsilon}^{2}
\end{array}\right]
$$

Submatrix $P$ represents the inconditional variance of the cyclical component and is estimated assuming the stationarity of that component. Since the trend and its slope are not stationary, it is not possible to estimate their variances in the same way. One alternative is to follow the proposal of Harvey and Phillips (1979), which considers extremely large numbers, with which the variance and covariance matrix approaches its exact value after several iterations. It is important to highlight that the state variables (trend and cycle) are not sensitive to these specifications.

\footnotetext{
9 Wada and Perron (2006) take as initial value of the slope the first rate of growth of the series. However, the growth of Peruvian GDP during the first periods is very irregular. Thus, we take an average.
} 


\subsection{Restrictions and initial conditions}

The proposed model, and in general the models with mixture of gaussian errors, present a parameter identification problem. The likelihood function remains constant given a permutation of their individual components, and the estimation parameters cannot be obtained. This problem is known as "label switching" and is analyzed by Hamilton et al. (2004). In the specific case of $p\left(y_{t} \mid Y_{t-1}\right)$ we obtain that:

$$
\begin{aligned}
p\left(y_{t} \mid s_{t-1}, s_{t}, Y_{t-1}\right) \operatorname{Pr}\left(s_{t-1}=i, s_{t}=j \mid Y_{t-1}\right) & \\
& +p\left(y_{t} \mid s_{t-1}, s_{t}, Y_{t-1}\right) \operatorname{Pr}\left(s_{t-1}=i^{*}, s_{t}=j \mid Y_{t-1}\right) \\
= & p\left(y_{t} \mid s_{t-1}, s_{t}, Y_{t-1}\right) \operatorname{Pr}\left(s_{t-1}=i^{*}, s_{t}=j \mid Y_{t-1}\right) \\
& +p\left(y_{t} \mid s_{t-1}, s_{t}, Y_{t-1}\right) \operatorname{Pr}\left(s_{t-1}=i, s_{t}=j \mid Y_{t-1}\right) .
\end{aligned}
$$

In consequence, it is not possible to identify the states $i$ and $i^{*}$ without carrying out a normalization. Wada and Perron (2006) impose restrictions in the parameters of the distributions with mixture of normals. And the restrictions vary for each of the G7 countries under analysis. For example, in the case of the United States, they assign a minimum probability $\left(\alpha_{2}=0.9\right)$ to the fact that the slope disturbances are in the low variance regime and that the maximum value of such variance is $\sigma_{v_{1}}^{2}=0.01$. We consider that for the Peruvian case, such values are very restrictive. We only impose as a restriction that the variances associated with the high volatility regime be higher than those associated with the low volatility regime, whereas the probability of being in the low volatility regime be at least 0.5 . More than a restriction, this represents a normalization of the parameters that does not affect the decomposition into trend and cycle.

\subsection{Smoothing}

The estimation process is completed with the inference on the state vector $x_{t}$ and on the probabilities associated with each regime $s_{t}$, taking into consideration all available information. That is, we aim to estimate $\operatorname{Pr}\left[s_{t}=j \mid Y_{T}\right] y x_{t \mid T}(1,2, \ldots, T)$. To this end, the smoothing algorithm developed by Kim and Nelson (1999b) is employed. The main steps are described as follows.

The first step in the smoothing process is to backwards estimate the state vector and its variance for each period $t=T-1, T-2, \ldots, 1$ on the basis of estimated values in the filtering process, according to the following algorithm:

$$
\begin{gathered}
x_{t \mid T}^{j k}=x_{t \mid t}^{j}+\widetilde{P}_{t}^{j k}\left(x_{t+1 \mid T}^{k}-x_{t+1 \mid t}^{j k}\right), \\
P_{t \mid T}^{j k}=P_{t \mid t}^{j}+\widetilde{P}_{t}^{j k}\left(P_{t+1 \mid T}^{k}-P_{t+1 \mid t}^{j k}\right) \widetilde{P}_{t}^{j k \prime},
\end{gathered}
$$

where $\widetilde{P}_{t}^{j k}=P_{t \mid t}^{j} F^{\prime}\left[P_{t+1 \mid T}^{j k}\right]^{-1}$, whereas $x_{t \mid T}^{j k}$ and $P_{t \mid T}^{j k}$ are the values taken by the state variables and their mean squared error, conditional to the availability of all information and that $S_{t}=j$ and $S_{t-1}=k$. 
In the second step, the probabilities associated with each regime are estimated. Here, the following derivation of the joint probability of $S_{t}=j$ and $S_{t+1}=k$ is made, conditional to the availability of all information:

$$
\begin{aligned}
\operatorname{Pr}\left(S_{t}\right. & \left.=j, S_{t+1}=k \mid Y_{T}\right)=\operatorname{Pr}\left(S_{t+1}=k \mid Y_{T}\right) \operatorname{Pr}\left(S_{t}=j \mid S_{t+1}=k, Y_{T}\right) \\
& \approx \operatorname{Pr}\left(S_{t+1}=k \mid Y_{T}\right) \operatorname{Pr}\left(S_{t}=j \mid S_{t+1}=k, Y_{t}\right) \\
& =\frac{\operatorname{Pr}\left(S_{t+1}=k \mid Y_{T}\right) \operatorname{Pr}\left(S_{t}=j, S_{t+1}=k \mid Y_{t}\right)}{\operatorname{Pr}\left(S_{t+1}=k \mid Y_{t}\right)}
\end{aligned}
$$

and

$$
\operatorname{Pr}\left(S_{t}=j, Y_{T}\right)=\sum_{k=1}^{M} \operatorname{Pr}\left(S_{t}=j, S_{t+1}=k \mid Y_{T}\right) .
$$

Since each state variable depends on its regime, $M \times M$ estimators of $x_{t \mid T}^{j k}$ and of $P_{t \mid T}^{j k}$ are generated, so that a collapsing process similar to the one previously described is undertaken, where:

$$
\begin{gathered}
x_{t \mid T}^{j}=\frac{\sum_{k=1}^{M} \operatorname{Pr}\left(S_{t}=j, S_{t+1}=k \mid Y_{T}\right) x_{t \mid T}^{i j}}{\operatorname{Pr}\left(S_{t}=j \mid Y_{T}\right)}, \\
P_{t \mid T}^{j}=\frac{\sum_{k=1}^{M} \operatorname{Pr}\left(S_{t}=j, S_{t+1}=k \mid Y_{T}\right)\left\{P_{t \mid T}^{j k}+\left(x_{t \mid T}^{j}-x_{t \mid T}^{i k}\right)\left(x_{t \mid T}^{j}-x_{t \mid T}^{i k}\right)^{\prime}\right\}}{\operatorname{Pr}\left(S_{t}=j \mid Y_{t}\right)} .
\end{gathered}
$$

Finally, the smoothed state vector $x_{t \mid T}$ is built as the weighted average of the $M$ vectors $x_{t \mid T}^{j}$, given their respective probabilities:

$$
x_{t \mid T}=\sum_{j=1}^{M} \operatorname{Pr}\left(S_{t}=j \mid Y_{T}\right) x_{t \mid T}^{j} .
$$

\subsection{Computation}

The program of the model is available to the public ${ }^{10}$ and has been built using GAUSS, taking as a basis the code written by Chang-Jin Kim in Kim and Nelson (1999b). We made variations in order to estimate all the models under consideration. In order to maximize the possibility of obtaining a global maximum in the likelihood function, we reestimated each model 900 times with different initial values which originate, in equal number, from the normal distributions $N(0,1), N(0,2)$ and $N(0,3)$. In each case, a convergence criterion 1e05 from the command optmum of Gauss has been used to optimize the likelihood function.

\footnotetext{
${ }^{10} \mathrm{http}: / /$ people.bu.edu/perron.
} 


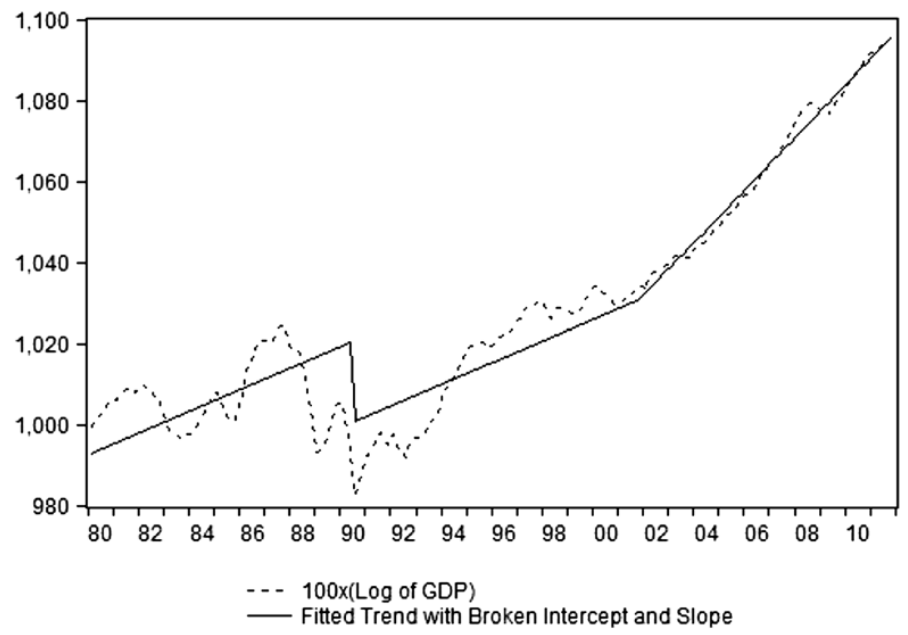

Fig. 1 Peruvian GDP and fitted broken trend

\subsection{The data}

The data utilized correspond to the seasonally adjusted quarterly series ${ }^{11}$ of the logarithm of GDP from 1980 to 2011, which is shown in Fig. 1. The source of information is the Peruvian Reserve and Central Bank. In terms of motivation about the presence of structural changes, Fig. 1 shows the possibility that the GDP may be approximated by a fitted trend with a broken intercept and a broken trend.

Peruvian GDP shows a very irregular behavior, as expected from a developing country. First, there are clear differences in the periods before and after 1990; and second, within each subperiod, the behavior of output has also been irregular, albeit less so.

In the early 1990s a process of significant economic adjustment took place, and at the same time a number of institutional reforms were enacted that drastically changed the dynamic of output. In the subperiod from 1980 to 1990 , the average growth rate of GDP was approximately $0 \%$ yearly. Large recessions occurred with an unusually high frequency and output was very volatile. In contrast, in later periods the average growth rate of GDP was more than $4 \%$ yearly, recessions were less frequent and had a lower magnitude, and output followed a more stable path.

Within each subperiod the behavior has also been irregular, as a result of recessions with varying origins and impact. For example, the 1983 recession, which was related to the "El Niño" phenomenon and a balance of payments crisis, produced a large contraction in output that did not recover until 1985. For their part, the big recessions of 1988-1989 and 1990, associated with periods of hyperinflation and internal conflict, produced contractions in output that were not overcome until

\footnotetext{
11 The UC model employed can admit the series with the seasonal component; however, we choose not to include that component in order to facilitate the estimation. Besides, the main concern is to identify the non-linearities in the trend and the asymmetry in the cycles.
} 
1995. From then on, the recessionary periods had a lower impact, although they did not share the same nature or consequences. For example, the recession of 1998 was linked to a banking crisis that had a negative influence on the long term growth rate; the 2000 recession corresponded to a period of political instability; and the 2009 recession, associated with the international financial and economic crisis, brought about a sharp contraction in output but it was rapidly overcome. A more detailed explanation of each of these recessions is provided in Dancourt et al. (1997) and Dancourt and Mendoza (2009).

Finally, but equally important, one has to take into consideration the monetary and fiscal reforms that were implemented in the 2001-2002 period, which led to an acceleration in the rate of growth of output.

In terms of econometrics, a rigorous analysis of the series would involve a test of stationarity; that is, to find out whether the series has a stochastic trend. The advantage of utilizing disturbances with a mixture of normals lies in the fact that they allow one to model both a stochastic and a deterministic trend. For example, if the probability of being in the high variance regime is very small and the other regime has a variance close to zero, a deterministic trend is generated, with shocks that produce a change in the level or slope. Even so, a unit root test would be useful in the identification, for in the analyzed models we consider that output has a double root. Using an $\mathrm{ADF}^{\mathrm{GLS}}$ test as in Elliott et al. (1996), we observe that the null hypothesis that the series is an $I(2)$ process is rejected at $5 \%$ but not at $1 \% .^{12}$ Although this result favors a single root in output, we retain the flexible specification of (1) to (5) as it is more general and does not generate an overidentification of the models, as is explained in the next section (see, in particular, Sect. 4.4).

\section{Results}

Before starting ${ }^{13}$ the analysis of the different models that are considered in the methodology, it is convenient to estimate a base model, UC-0, that does not include any mixture of normals, and follows the specification of Clark (1987). The obtained cycles capture the big recessions of 1988-1989 and 1990 well, but henceforward the cycle presents a positive bias; for example during the recessions of 1998 and 2009 output is above its potential or trend level. On the other hand, the cycles are long and have a large amplitude ${ }^{14}$, reaching a maximum deviation of $10 \%$ in the mid1990s.

\footnotetext{
12 The $t$-statistic - including and intercept and a time trend-for $H_{0}: I(1)$ process is -1.297 implying a non-rejection. The $t$-statistic of the $H_{0}: I(2)$ process is -2.076 implying a rejection at $5 \%$ but not at $1 \%$. Application of a rolling $\mathrm{ADF}^{\mathrm{GLS}}$ statistic allows similar results. However, Oh and Zivot (2006) find evidence rejecting the imposition of two unit roots.

13 We only include tables and figures concerning the selected model (UC-CN). Other results are available upon request or they may be found in the Working Paper version; see Guillén and Rodríguez (2013).

14 Following definition of Castillo et al. (2007), amplitude is the distance between the maximum and minimum values of the cycle.
} 
Estimations of the UC-0 model show that the cyclical component presents a large and significant standard deviation, whereas the standard deviations of the other components are close to zero. Hence, short term shocks end up explaining almost $100 \%$ of the deviations of output. With respect to the autoregressive coefficients of the cycle, they add up to 0.932 ; that is, the cycle practically does not revert to mean. Besides, an analysis of its associated characteristic polynomial indicates that the roots are not complex, and hence, that the stationary component does not follow a cyclical pattern. These results, together with the upward bias in the cycles in periods after 1990, would indicate that the Clark (1987) specification does not seem adequate for modeling Peruvian GDP.

\subsection{Models with one mixture of normals}

Among the proposed models, the first estimation corresponds to the UC-C model that contains a mixture of normals in the disturbance of the cyclical component $\left(\epsilon_{t}\right)$. The cyclical component is negative during the recessive periods. Moreover, the cyclical component is most of the time below the steady state ${ }^{15}$; only during periods of high growth, as in 1986-1987 or 2008, does it take positive values. That is, there is a large asymmetry in the cycles. The obtained decomposition is similar to that which can be obtained through the "plucking" model of Kim and Nelson (1999a), where output grows most of the time at its potential level or "ceiling", and only in recessive periods does it deviate negatively from trend.

It is observed that recessions are associated mainly with periods of high variance. In contrast to the "plucking" model of Kim and Nelson (1999a), the observed probabilities do not correspond exactly to recession and normal periods, but rather to periods of high and low volatility. In general, the higher volatility is associated with a strong drop in output and its subsequent recovery, but can also take place in normal periods. For instance, in the first quarter of 1994, seasonally adjusted GDP grew $5.48 \%$ and in 2002, after a brief decrease, there was a swift recovery in output and its average variation in absolute terms was of $3.53 \%$. This explains why those periods have a higher than 0.5 probability of being within the high variance regime.

Estimations of this model reveal: the standard deviations of the disturbances, the autoregressive coefficients and the probability associated with being in the low variance regime. The existence of asymmetry in cycles is confirmed; the standard deviation of the cyclical component associated with the high variance regime $\left(\sigma_{\epsilon_{2}}^{2}\right)$ is much higher than that associated with the low variance regime $\left(\sigma_{\epsilon_{1}}^{2}\right)$, although the restriction admits that they can be almost equal. Both standard deviations are significant and relatively higher than the others, whereas the standard deviation of the trend level $\left(\sigma_{\eta}\right)$ is statistically non-significant. This translates into a smooth behavior of the trend. With respect to the autoregressive parameters $\left(\phi_{1}, \phi_{2}\right)$, they add up to 0.952 ; that is, short-term shocks generate cycles of high persistence or duration. On the other hand, real roots of the characteristic polynomial are obtained, and hence, the stationary component does not follow a properly cyclical pattern.

\footnotetext{
15 Steady state is defined as the point at which the cyclical component is zero or GDP is exactly at its potential level.
} 
Finally, the probability of being in the low variance regime $\left(\alpha_{1}\right)$ is of $75 \%$ and significant; that is, the economy is most of the time in "normal" periods. Besides, this probability implies that the results obtained are not sensitive to the imposed restriction (probability higher than $50 \%$ ).

An additional estimation was carried out, which imposed a restriction of zero on the estimator of the standard deviation of the trend, and no major changes in the other estimators were found. On the other hand, the standard deviation of the slope is relatively small and significant, which would indicate a stable long-term growth rate. The evolution of the slope shows a decline until the early 1990s, a slight recovery during that decade, and an acceleration starting in 2000.

In order to assess the importance of short or long term shocks we weighted the variance of the cyclical component $\left(\sigma_{\epsilon}^{2}\right)$ given the probabilities, from which we obtain that it represents $93 \%$ of the variance in output. In contrast, the variance of the slope explains only $0.24 \%$ of the variability of output, and the remaining percentage is explained by the shocks of the measurement equation $\omega_{t}$. Even in periods of low volatility, the variance of the cyclical component is higher. In other words, there is a total domination of short-term shocks on output fluctuations.

The second estimated model was an UC-N model, which contains a mixture of normals in the disturbance of the trend $\left(\eta_{t}\right)$. The observed recessionary cycles mostly coincide with recession periods; although, in contrast to the previous model, these cycles have lower duration and amplitude. The cycles associated with the large recessions of 1988-1989 and 1990 do not show large deviations with respect to trend. However, strong drops in the trend component are observed. That is, under this specification, the drops in output during the recessions of 1988-1989 and 1990 would be associated with long term shocks that prompted abrupt changes in the trend level. The probability of being in the higher variance regime is higher during recession periods. For example, in the recession of 1998 the drop in the cycle is lower than during most of other recessions. However, this period is associated with a state of high volatility; that is, in 1998 not only a did a short-term shock take place, but also a real shock with effects in the long term.

Just as in the previous model, the periods of high volatility but no recession, such as 1994 and 2002, are related to regimes of high variance. Although in this case, they are related to long-term shocks. An important detail is the measurement of the cycle during the recession of 2009. The recessionary cycle shows a large magnitude, and the drop is even larger than that of 1998 . However, the probability of a trend change is low; that is, the shock was mainly transitory.

Regarding the estimates, the standard deviation of the trend in the highest variance regime $\left(\sigma_{\eta_{2}}^{2}\right)$ is significant, just as the probability of being in a low variance regime $\left(\alpha_{1}\right)$. On the contrary, the standard deviation of the lower variance regime is non-significant $\left(\sigma_{\eta_{1}}^{2}\right)$. Regarding the standard deviation of the slope $\left(\sigma_{v}\right)$, this is relatively small and significant. This indicates that the trend component, most of the time, is explained by the variance of the trend or the long term growth rate. And only in periods of high volatility, that have a lower probability, do shocks on the level and slope of the trend take place. Thus, the latter behaves as if it were a process $I(2)$. On the other hand, the standard deviation of the cyclical component is 
significant $\left(\sigma_{\epsilon}\right)$ just as the autoregressive coefficients $\left(\phi_{1}, \phi_{2}\right)$, whose sum is 0.68 , this explains the rapid convergence of the cycles.

Taking into consideration that the standard deviation of the measurement equation and the standard deviation of the trend in the low variance regime are not significant, two additional estimations are carried out imposing the restriction of nullity on one and both coefficients. ${ }^{16}$ In all cases, the parameters do not show important changes with respect to the initial estimations.

In assessing the relative weight of variances, we find that the long-term shocks explain $83 \%$ of output's variability, and short-term shocks the remaining $17 \%$. That is, real or long-term shocks have a higher preponderance, but the shocks of the cyclical component are still important, especially during periods of low trend volatility, where they explain $96 \%$ of the variation in output. These shocks could be the origin of the 2009 recession, which does not seem to have had a relevant impact on long-term growth.

A striking result is the behavior of the slope or long-term growth rate of output. It features a cyclical behavior with peaks in 1995 and 2007, and troughs in 1983, 1989 and 2000. These periods, excluding 2007, coincide with the timing of cycles for the Peruvian economy provided by Castillo et al. (2007), who utilize the Baxter and King (1999) filter. Hence, if the UC-N model were appropriate, it would be characterizing an economy whose apparent cycles are actually productivity shocks on the growth rate.

A third estimated model was an UC-P model ${ }^{17}$, which features a mixture in the disturbance of the slope $\left(v_{t}\right)$. That is, we assume that there exists a period of high volatility in the shocks that affect the slope or long-term growth rate. This specification achieves a decomposition in trend and cycle similar to that found in the model UC-N, due to the fact that the asymmetries are caused by long-term shocks as well. In the decomposition of the cycle, one can observe that it tends to overestimate the magnitude of the expansion in the early 1980s and does not identify the recessions of 1990 and 1998.

In analyzing the probabilities associated with each regime we observe that only during the big recessions (1988-1989, and 1990) did the growth rate of output be in the high-volatility regime. This model presents a probability associated with high variance periods of barely $5.7 \%$, much lower than that of previous models, whose probabilities were around $25 \%$. This would indicate that Peruvian GDP, except in extraordinary situations such as the late 1990s, does not admit discrete changes in its long-term growth rate.

Estimates show that the standard deviation of the slope associated with "normal" periods is non-significant $\left(\sigma_{v_{1}}^{1}\right)$. Hence, a second estimation is carried out by imposing a nullity restriction on this estimator, without affecting the value of the

\footnotetext{
16 Additionally, an estimation with a deterministic trend was carried out. The obtained results did not diverge significantly from the parameters found for the other estimations. For example, the variance of the trend goes from 4.7 to 5, whereas the variance of the cyclical component goes from 1.07 to 1.25. The estimated slope is of 1.1 , which is close to the average of the stochastic trend of the other models. The decomposition of the cycles did not suffer significant changes.

17 From the models with a mixture of normals, this is the one with a higher sensitivity both in the filter and the smoothing algorithms.
} 
other estimators. The standard deviation of the cyclical component is significant $\left(\sigma_{\epsilon}\right)$ just as the autoregressive coefficients, and they add up to 0.77 , which implies cycles of low duration. On the other hand, the standard deviations of the trend $\left(\sigma_{\eta}\right)$ and the slope during periods of high volatility $\left(\sigma_{v_{2}}^{1}\right)$ are significant. In a similar way to the previous model, this would imply a double root in GDP. However, the probability associated with high variance periods is very low and hence there would be no problems of over-specification.

Long term shocks represent $76.5 \%$ of output variance. Again, the modeling of asymmetries in the long term component implies a predominance of real shocks. But, if only low volatility periods are analyzed, the situation is reversed and the cyclical component represents $54.4 \%$ of output variance. This share is lower than that found in the UC-N model, in which in "normal" times the variance of output is only explained by shocks to the cyclical component. This would imply that the level of trend presents a higher volatility than its slope. And also, if large productivity shocks take place, they affect with a higher probability the level of long term output, rather than its growth rate.

The slope resulting from this specification represents two abrupt collapses, the first during the 1988-1989 recession, when the long term growth rate decreased by up to $8 \%$, and the second during the 1990 recession, when a decrease of $10 \%$. It can be difficult to justify the magnitude of these declines, but the negative sign of the slope is consistent with a scenario of deep economic and political crisis that led to a destruction in the economy's production capabilities.

After carrying out the estimations that involve only one mixture of normals, some comments are on order. First, the specifications of asymmetries in the cyclical or long term components lead to different results in the estimated parameters and in the decomposition of cycles. This affects the relative weight of short or long term shocks with respect to fluctuations in output. Second, the high variance component, whatever its specification, tends to absorb most of the volatility of output. And third, the specification does not change in a significant way the ability of the model to generate negative cycles consistent with periods of recession, although the amplitude of the cycles is affected.

\subsection{Models with two mixtures of normals}

The previous analysis is complemented with estimations that combine two mixtures of normals. The first corresponds to the model UC-CN, which has a normal mixture in the disturbances of the cyclical and the trend level components $\left(\eta_{t}, \epsilon_{t}\right)$. When compared to the other models, this specification reaches the highest level of the likelihood function, which would indicate a better approximation to the datagenerating process. When observing the estimators provided in Table 1, one finds that the significance of the standard deviation of the trend associated with the low volatility regime $\left(\sigma_{\eta_{1}}^{2}\right)$ is strongly rejected, as well as the standard deviation of the measurement equation $\left(\sigma_{\omega}\right)$. Hence, two additional estimations are computed and one finds that the results are not sensitive to nullity restrictions on $\sigma_{\eta_{1}}^{2}$ and $\sigma_{\omega}$. 
Table 1 Estimates parameters of UC-CN model

\begin{tabular}{|c|c|c|c|c|c|c|}
\hline & \multicolumn{2}{|l|}{ UC-CN 1} & \multicolumn{2}{|l|}{ UC-CN 2} & \multicolumn{2}{|l|}{ UC-CN 3} \\
\hline & Coefficient & $t$ statistic & Coefficient & $t$ statistic & Coefficient & $t$ statistic \\
\hline$\sigma_{\eta_{1}}^{2}$ & 0.008 & 0.124 & & & & \\
\hline$\sigma_{\eta_{2}}^{2}$ & 6.112 & 1.281 & 6.111 & 1.044 & 6.115 & 1.395 \\
\hline$\sigma_{\epsilon_{1}}^{2}$ & 1.072 & 6.801 & 1.072 & 6.649 & 1.072 & 6.933 \\
\hline$\sigma_{\epsilon_{2}}^{2}$ & 3.795 & 3.730 & 3.795 & 3.295 & 3.795 & 3.793 \\
\hline$\sigma_{\nu}$ & 0.109 & 1.385 & 0.109 & 1.457 & 0.109 & 1.521 \\
\hline$\sigma_{\omega}$ & 0.010 & 0.165 & 0.010 & 0.085 & & \\
\hline$\phi_{1}$ & 1.416 & 11.703 & 1.416 & 9.287 & 1.416 & 12.377 \\
\hline$\phi_{2}$ & -0.519 & -4.698 & -0.519 & -3.648 & -0.519 & -4.816 \\
\hline$\alpha_{1}$ & 0.798 & 5.426 & 0.798 & 4.212 & 0.798 & 5.614 \\
\hline$\alpha_{2}$ & 0.903 & 6.935 & 0.903 & 5.422 & 0.903 & 7.473 \\
\hline $\ln (L)$ & -291.662 & & -291.662 & & -291.662 & \\
\hline
\end{tabular}

$\ln (L)$ is the $\log$ of the maximum likelihood value

The standard deviation of the trend associated with the high volatility regime is not significant $\left(\left(\sigma_{\eta_{2}}^{2}\right)\right.$. However, the complement of its probability of occurrence $\left(\alpha_{2}\right)$ is, and hence the probability that the trend is in a high volatility period is (0.097). That is, there is a change in the trend regime of the trend level variance, but it is difficult to identify the variance coefficients. This may be due to a highly volatile behavior of the shocks to the trend even in high variance periods, as well as to a certain degree of sensitivity of the decomposition algorithm. ${ }^{18}$ Over-identification issues in the model can be excluded, since, if both types of mixture (in the trend and in the cycle component) were not combined, the UC-C or UC-N models would result. These models present a decomposition that differs from that obtained from the present model.

Regarding the other estimators, one observes that the slope presents a nonsignificant standard deviation $\left(\sigma_{v}\right)$. However, this is not constant, since we found a strong rejection when the model was estimated under this restriction. Hence, despite the non-significance, the stochastic slope that shows the lower variance in comparison to the other components was retained. Regarding the cyclical component, the standard deviations of the low variance $\left(\sigma_{\epsilon_{1}}^{2}\right)$ and high variance $\left(\sigma_{\epsilon_{2}}^{2}\right)$ regimes are significant and one is much smaller than the other. That is, there are asymmetries in the cycles. On the other hand, the probability that the cycle is in a low variance regime $\left(\alpha_{1}\right)$ is significant and higher than in the UC-C model. This would indicate that by including two normal mixtures, one would be better identifying the high variance regimes, which affect not only the cycle (as in the UC-

\footnotetext{
${ }^{18}$ The estimations of this model led to another maximum in the likelihood function (-290.46), whose estimators of variance in trend were significant and showed a smoothing similar to the one presented. However, the smoothed cycles were explosive. We found that the smoothing algorithm was sensitive to one of the variances of the cyclical component that was close to a value of zero.
} 
C model), but also the trend. Finally, the autoregressive parameters are significant and add up to 0.897 , which would indicate a certain degree of persistence in shortterm shocks.

The contribution of short term shocks with respect to the variance of output is of $51.3 \%$. This result is interesting, as the model does not impose restrictions that condition the relative importance of short or long term shocks as the specifications of Beveridge and Nelson (1981) or Clark (1987) do. Under this model, the shocks to the cyclical component are as important as the shocks to the trend component.

As can be seen on Fig. 2, the trend behaves in a very smooth manner, with the exception of the periods in the early 1990s when a negative change in its level is evident. In consequence, the trend of output appears to behave as a non-stochastic trend during most of the time, and only during periods of high volatility do large productivity shocks occur that can have an effect on the trend level. This is consistent with the positions of Perron (1989) and Perron and Wada (2009).

With respect to the decomposition of cycles, we can observe three complete cycles are generated. The first, from 1980 until the second quarter of 1986, with an amplitude of $16.5 \%$. The second, from the third quarter of 1986 to the third quarter of 1994 with an amplitude of $23.8 \%$. And the third, from the fourth quarter of 1994 to the third quarter of 2006 with an amplitude of $11 \%$. The timeline and order of amplitude of these cycles resembles those found by Castillo et al. (2007), although the magnitude reported in the present study is larger.

Regarding recessions, the model detects most of the recessive periods. The recession with the largest magnitude was that of 1988-1989, when output deviated $20 \%$ from its potential level. Later, in 1990, the economy underwent a structural change and the structural component fell sharply. From then onwards, the behavior of the trend is more stable. The recessions of 1992 and 2009 are identified as negative cycles, whereas during the recession of 1998 the cyclical component barely


Fig. 2 UC-CN model, trend and cycle 


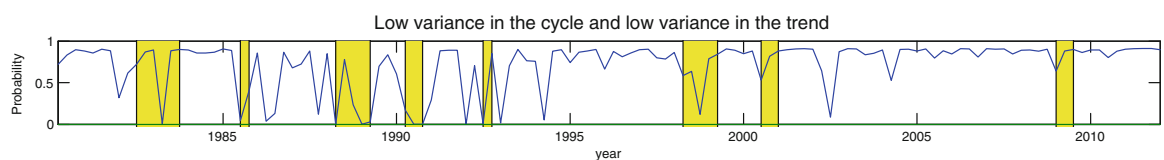

Low variance in the cycle and high variance in the trend

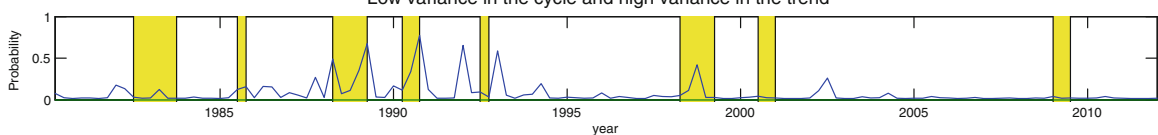

High variance in the cycle and low variance in the trend

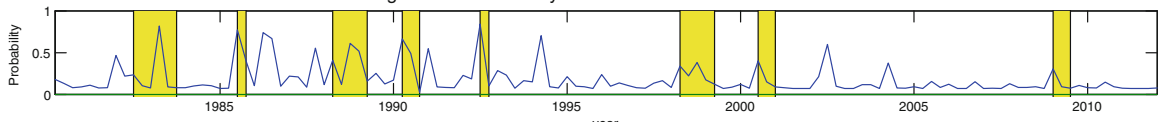

High variance in the cycle and high variance in the trend

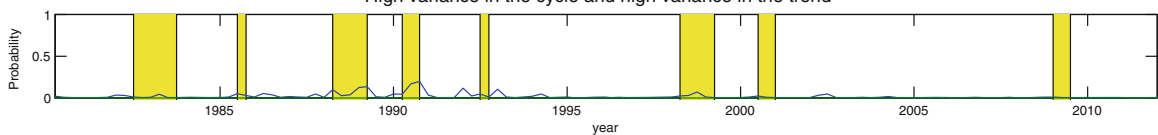

Fig. 3 UC-CN model, state probabilidades

reached negative values, although a decrease in its path was evident. On the other hand, the largest identified expansionary cycles are 1987, 1997 and 2008, which are consistent with empirical evidence reported by Dancourt and Mendoza (2009).

Regarding the high and low variance regimes, the large recessions of the early and late 1990s are associated both with regimes of high variance both in the trend as in the cyclical component (see Fig. 3). That is, not only did shocks take place that affected long-term growth, but also did short-term measures that affected the path of cycles. On the other hand, the recessions of 1998 and 2009 are not associated with high variance periods with a probability higher than $50 \%$. Regarding the recession of 1998, the graph of probabilities indicates that period was not "normal", but it is not possible to identify whether it corresponds to a regime of high variance in the cycle, in the trend, or in both. At the same time, the recession of 2009 is not associated with any regime of high variance; that is, it was a temporary shock.

The slope or long term growth rate presents an average quarterly growth rate between 0.6 and $0.8 \%$ from 1980 until 2011, with slight decreases during recessive periods (see Fig. 4). In contrast, from 2002 on it starts to accelerate until it reaches quarterly rates of $1.6 \%$ or yearly rates of $6.5 \%$, which is consistent with the high growth experienced by the country in the last years.

The fifth estimated model was UC-CP, which contains a mixture of normals in the disturbances to the cyclical component and to the trend slope $\left(\epsilon_{t}, v_{t}\right)$. The model presents a decomposition of trend and cycle that is very similar to the model UC-C. In the same way, the high variance regimes are only associated with the asymmetry of the cycles, mainly during recessive periods. And the path of the slope follows the same pattern as in model UC-C.

Regarding the estimated coefficients, the standard deviations of the cyclical component in the high variance regime $\left(\sigma_{\epsilon_{2}}^{2}\right)$ are significant, as well as the complement of its associated probability $\left(\alpha_{1}\right)$ and different from one. For their part, the standard deviations of the cycle in the low variance regime $\left(\sigma_{\epsilon_{1}}^{2}\right)$, of the trend 


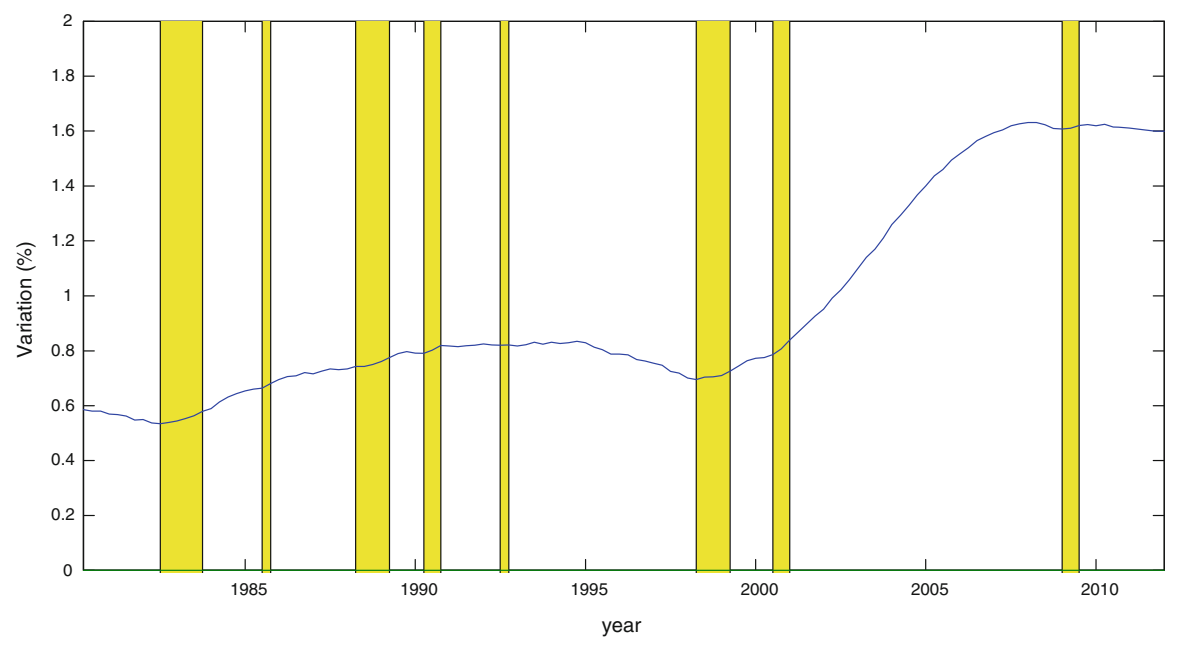

Fig. 4 UC-CN model, growth rate of the trend

$\left(\sigma_{\eta}\right)$ and of the slope for both regimes $\left(\sigma_{v_{1}}^{2}, \sigma_{v_{2}}^{2}\right)$ are not significant. Moreover, the probability of occurrence of the low variance regime in the slope is almost 1 and non-significant.

Taking this into consideration, two additional estimations were made which imposed, first, a restriction of nullity on the standard deviation of the trend $\left(\sigma_{\eta}\right)$ and then, due to its non-significance, another restriction on the standard deviation of the measurement equation $\left(\sigma_{\omega}\right)$. In contrast to the previous models, the estimators are affected, although not the decomposition. This would indicate a higher sensitivity of the model. After the restrictions are made, all parameters become significant, although the standard deviations $\left(\sigma_{v_{1}}^{2}, \sigma_{v_{2}}^{2}\right)$ of the slope are almost the same and their probability associated with the low variance regime $\left(\alpha_{2}\right)$ is higher than 0.9 . Moreover, the values reached are similar to those of the UC-C model. For example, in both models the standard deviation of the cycle in the high variance regime $\left(\sigma_{\epsilon_{2}}^{2}\right)$ and the complement of its associated probability $\left(\alpha_{1}\right)$ are almost the same. Besides, in this model as in the UC-C, the characteristic polynomial of the cycle presents non-imaginary roots, and the sum of all autoregressive coefficients is 0.930 . All this seems to indicate that the mixture of the cyclical component completely dominates the mixture of the slope, and that there is an over-specification when both mixtures are specified jointly.

The sixth estimated model was UC-NP, which presents a mixture of normals in the disturbances of the trend level and slope $\left(\eta_{t}, v_{t}\right)$. The decomposition features two characteristics. The first one is that cycles are short and the trend fits closely to the output. The second is that, although most of the negative cycles coincide with periods of recession, the magnitude of the falls is relatively small. These two characteristics can be explained by the higher relative weight of long term shocks on the variation of output. As can be estimated from the parameters shown on Table 2, 
the joint variance of shocks to the trend $\left(\sigma_{\eta_{1}}^{2}, \sigma_{\eta_{2}}^{2}\right)$ and its slope $\left(\sigma_{v 1}^{2}, \sigma_{v 2}^{2}\right)$ explain $89.5 \%$ of the variation in output.

On the other hand, the standard deviation of the cyclical component $\left(\sigma_{\epsilon}\right)$ is lower than the other deviations, whereas the sum of the autoregressive coefficients is of 0.28 , that is, the cycles are not only small, but they also revert more quickly to the mean in comparison to other models. This represents a big difference with respect to other models. For example, in the UC-N and UC-P models which take into consideration mixtures on long term disturbances, the sum of the autoregressive coefficients is of 0.69 and 0.77 respectively. Yet by combining both mixtures one obtains cycles with a much shorter duration. This would indicate that, if this model were correct, the previously described persistence in the cycle itself would correspond to long-term shocks that occur during "atypical" periods. As to the regimes of high and low variance, it is more likely that the transition between them is caused by shocks to the trend $\left(1-\alpha_{1}\right)$ than by shocks to the slope $\left(1-\alpha_{2}\right)$.

The results obtained do not deviate significantly from those obtained in models UC-N and UC-P. Nevertheless, in combining both mixtures in the disturbances to the trend and the slope, one finds a higher relevance of the former, and in consequence, to model only mixtures in the slope would not yield a good specification.

Regarding the slope, it takes negative values during the great recession of the late 1980s, a similar result to that of model UC-P, although with lower magnitude and volatility. Besides, it shares the cyclical evolution of the model UC-N.

Starting from the inclusion of a second mixture of normals, one can make the following remarks. First, the methodology is still useful in obtaining cycles that fit most of the expansion or recession periods of the Peruvian economy. And second, the duration and amplitude of the cycles differ depending on whether one admits asymmetries in the shocks of the trend component, or on those of the cyclical component as well. If one models allowing mixtures in both kinds of shocks simultaneously, one obtains that the short term shocks are as important as those of the long term when explaining the fluctuations in output.

\subsection{Model with three mixtures of normals}

Finally, we estimated the UC-CNP model which has a mixture of normals in the disturbances or the cyclical, trend and slope components $\left(\epsilon_{t}, \eta_{t}, v_{t}\right)$. For estimations, the variances of the cyclical and trend components are both significant, and the variance of the measurement equation is not significant, whereas regarding the slope, only the variance in the low-intensity regime is significant and associated with a probability of almost unity.

Taking into consideration the non-significance of the standard deviation of the measurement equation $\left(\sigma_{\omega}\right)$, we did an additional estimation imposing a nullity restriction on this parameter. The additional estimation presents a higher value of the likelihood function, and thus it does not represent a better specification than the non-restricted model. In contrast to the previous models, the nullity restriction on a non-significant parameter whose value is close to zero changes the magnitude of the 
other parameters in a significant way. This may be due to the substantial sensitivity of the initial values with respect to the probabilities of regimes and the lack of convergence in the final parameters.

On the other hand, short term shocks represent $45.4 \%$ of the variation in output. Despite the fact that the addition of mixtures of normals in both long term components could condition the relative weight of shocks, the cyclical component is still important in explaining output fluctuations. Moreover, in normal periods, short terms shocks explain more than $60 \%$ of the variance in output.

Taking into consideration that the standard deviation of the slope in high volatility periods $\left(\sigma_{v_{2}}^{2}\right)$ is non-significant, an additional estimation imposing a nullity restriction on this parameter could be formulated. To do this would lead to the UC$\mathrm{CN}$ model. However, if one observes the decomposition of cycles and the probabilities of the states, there are clear differences with respect to the UC-CN model. First, the cycles are shorter and have less amplitude, and second, the higher volatility is associated with shocks on the trend, rather than on the cyclical component. On the other hand, the slope presents the cyclical behavior that has been previously commented with negative values during the big recessions of the late 1980 s and early 1990s.

The divergence in the decomposition between this model and UC-CN, even if the additional mixture appears not to be relevant, could be explained by the sensitivity of the estimation algorithm. By including three mixtures, a global maximum is not reached and hence neither is the decomposition that would more tightly fit the data generating process.

In general, the diverse estimated models present different decompositions of trend and cycle. It is therefore necessary to establish model selection criteria, which are reviewed in the following section.

\subsection{Assessment and selection of models}

Before presenting the statistical tests that allow one to assess the convenience of a given model over another, it is convenient to make a brief comparison with some theoretical predictions and empirical regularities regarding the decomposition of cycles, as well as other methods that are also usually employed.

First, modern macroeconomic theory predicts that both short terms and permanent shocks are relevant in explaining output fluctuations. Additionally, if the existence of the "plucking" effect is considered, it would follow that short term shocks are important during recessions, whereas permanent shocks would be relevant in normal times. Table 2 shows that only the UC-CN and UC-CNP models follow this pattern. Models UC-C and UC-CP feature an absolute domination of short term shocks ${ }^{19}$; that is, these models may be overestimating the cyclical component and its relative importance in the fluctuations of the economy. In the

\footnotetext{
${ }^{19}$ In both models the variance of the irregular component $\sigma_{w}^{2}$ is different from zero. Even when a restriction of nullity on that variable is imposed, all the variation of the component is transferred to the cyclical component, instead of the long-term component.
} 
Table 2 Components participation on the variance of output

\begin{tabular}{cccccccc}
\hline & UC-C $(\%)$ & UC-N $(\%)$ & UC-P $(\%)$ & UC-CN $(\%)$ & UC-CP $(\%)$ & UC-NP (\%) & UC-CNP (\%) \\
\hline$\sigma_{\eta}^{2}$ & 0.0 & 82.6 & 19.7 & 48.5 & 0.0 & 79.2 & 49.9 \\
$\sigma_{\epsilon}^{2}$ & 93.1 & 16.6 & 23.5 & 51.3 & 93.0 & 10.5 & 45.4 \\
$\sigma_{v}^{2}$ & 0.2 & 0.8 & 56.8 & 0.2 & 0.2 & 10.3 & 4.6 \\
$\sigma_{\omega}^{2}$ & 6.7 & 0.0 & 0.0 & 0.0 & 6.8 & 0.0 & 0.0 \\
\hline
\end{tabular}

other models, long-term shocks predominate, although the variance of the cyclical component is between 10 and $24 \%$.

Second, the evidence supports the fact that the cycles behave differently in emerging and developed countries, with the former showing a higher volatility. Some theories attempt to explain these differences. One of them is Aguiar and Gopinath (2007), which presents a model where the shocks to the growth rate of output are the main factor behind cycles in emerging countries. What is interesting about this study is that it takes into account countries of the Latin American region, including Peru. Among the estimated models, those that admit a change in the trend level (with the exception of the UC-CN model) present a slope or long-term growth rate with cyclical behavior. This would be consistent with the proposal of Aguiar and Gopinath (2007). However, in the Peruvian case one finds that the fluctuations in output are explained, in atypical times, by large shocks to the trend level and not to the long term growth rate; whereas in normal periods, both permanent shocks to the growth rate as well as shocks to the transitory component are relevant.

Third, regarding the specification of models, all of them include potentially a double unit root in the trend of output. The results show that this type of specification is convenient when one includes mixtures of normals in the modeling of the trend. Let us consider the following examples. First, assume that there is a mixture in the trend $\left(\tau_{t}\right)$, that is, the model UC-N. If the results indicate that most of time $\sigma_{\eta_{1}}^{2}=\sigma_{\eta_{2}}^{2}=0$ and changes come from $\sigma_{v}^{2}$, it means that we have an I(1) process. Second, assume a mixture in $\beta_{t}$. If most of times $\sigma_{v_{1}}^{2}=0$ and there is only a $5.0 \%$ of probability that $\sigma_{v_{2}}^{2}>0$, it means that most of the times the process is I(1) but there is a small probability that the process is I(2). As third example, let us consider a double mixture (in $\tau_{t}$ and $\beta_{t}$ ). We may obtain that the estimates of $\sigma_{\eta_{1}}^{2}>0$ and $\sigma_{\eta_{2}}^{2}>0$ and statistically significant, however the variance of the slope $\left(\beta_{t}\right)$ most of times is zero and there is a small probability where $\sigma_{v_{2}}^{2}>0$. In this case, we have again an $I(1)$ process most of time but there is an $I(2)$ process with a small probability. Finally, consider the case of the UC-CN model. The results (Table 1) indicate that $\sigma_{\eta_{1}}^{2}=\sigma_{\eta_{2}}^{2}=0$ whereas $\sigma_{\epsilon_{1}}^{2}>0$ and $\sigma_{\epsilon_{2}}^{2}>0$ are statistically significant. Regarding $\sigma_{v}^{2}$, it is statistically not significant at $10.0 \%$. If it is the case, we have an I(0) process altered for some abrupt structural changes as in Perron (1989). However, $\sigma_{v}^{2}$ is statistically significant at $13.0 \%$. If we accept this result (marginally at $10.0 \%$ ), we have an $I(1)$ process. 
Table 3 Business-cycles duration

\begin{tabular}{|c|c|c|c|c|c|c|c|c|}
\hline & UC-0 & $\mathrm{UC}-\mathrm{C}$ & UC-N & UC-P & $\mathrm{UC}-\mathrm{CN}$ & UC-CP & UC-NP & UC-CNP \\
\hline \multicolumn{9}{|c|}{ Autoregressive parameters } \\
\hline$\phi_{1}$ & 1.353 & 1.496 & 1.361 & 1.276 & 1.416 & 1.506 & 1.159 & 1.276 \\
\hline$\phi_{2}$ & -0.432 & -0.544 & -0.676 & -0.504 & -0.519 & -0.553 & -0.878 & -0.770 \\
\hline \multicolumn{9}{|c|}{ Roots of the inverse polynomial } \\
\hline$\lambda_{1}$ & 0.837 & 0.875 & $0.68+0.5 \mathrm{i}$ & $0.64+0.3 \mathrm{i}$ & $0.71+0.1 \mathrm{i}$ & 0.873 & $0.58+0.7 i$ & $0.64+0.6 \mathrm{i}$ \\
\hline$\lambda_{2}$ & 0.515 & 0.621 & $0.68-0.5 \mathrm{i}$ & $0.64-0.3 \mathrm{i}$ & $0.71-0.1 \mathrm{i}$ & 0.634 & $0.58-0.7 \mathrm{i}$ & $0.64-0.6 \mathrm{i}$ \\
\hline \multicolumn{9}{|c|}{ Implicit duration of cycles (years) } \\
\hline & & & 2.6 & 3.5 & 8.5 & & 1.7 & 2.1 \\
\hline
\end{tabular}

The implicit duration of cycles is given by $d=\frac{2 \pi}{\theta}, \cos (\theta)=\frac{a}{R}$, where $a$ and $R$ are the real part and the module of root $\lambda$

Fourth, one expects that the short term component, which follows an $\mathrm{AR}(2)$ process, has a cyclical pattern characterized by the presence of imaginary roots in its characteristic polynomial. Table 3 shows the roots of each polynomial and the implicit duration of the cycles. Both the basis model, as well as the UC-C and UC$\mathrm{CP}$ models show real roots, and thus they may not be adequate for the identification of the short term cyclical component.

On the other hand, there is an important difference between the UC-CN model and the rest; the former presents cycles of long duration, practically exceeding the conventionally accepted limit (32 quarters). In this model, the first cycle lasts from 1980 to 1986 and registers an amplitude of $16 \%$, the second cycle starts in 1986 and ends in 1994 with an amplitude of $23.8 \%$; and the third cycle comprises the 1994-2006 period with an amplitude of $11 \%$. This timeline is consistent with the estimation of complete cycles by Castillo et al. (2007), where the most important stylized fact is a reduction in the amplitude of the cycles and their higher duration in the last decade; that is, the Peruvian economy currently fluctuates closer to its steady state and presents higher persistence.

Fifth, there are different methods for separating the trend and cyclic components. Table 4 shows the simple correlations between these methods and the estimated models. The numbers in boldface show the higher correlation with respect to each method. The first four methods in the table correspond to estimations of deterministic trends, where $t$ is a linear trend, $t^{2}$ is a squared trend, $t_{q_{1}}$ is a linear trend with a break in the third quarter of 1990, and $t_{q_{2}}$ adds a break in the slope in the first quarter of 2002.

The two first methods $\left(t, t^{2}\right)$ have a better correlation with the UC-C and UC-CP models, and in a lesser degree with the UC-CN model. However, Fig. 5 shows that the cycles of the $t$ and $t^{2}$ methods tend to overestimate the expansionary periods previous to 1990 and after 2007; for example, they do not identify the 2009 recession. $^{20}$

\footnotetext{
${ }^{20}$ In Figs. 5, 6 and 7, dotted line represents the cyclical component obtained from the UC-CN model.
} 
Table 4 Correlations with others methods

\begin{tabular}{llllllll}
\hline & UC-C & UC-N & UC-P & UC-CN & UC-CP & UC-NP & UC-CNP \\
\hline$t$ & 0.81 & 0.28 & 0.29 & 0.54 & 0.81 & 0.06 & 0.51 \\
$t^{2}$ & 0.88 & 0.42 & 0.37 & 0.66 & 0.87 & 0.15 & 0.60 \\
$t_{q_{1}}$ & 0.65 & 0.41 & 0.51 & 0.80 & 0.65 & 0.05 & 0.67 \\
$t_{q_{2}}$ & 0.84 & 0.50 & 0.62 & 0.94 & 0.84 & 0.17 & 0.83 \\
HP 1600 & 0.71 & 0.69 & 0.50 & 0.76 & 0.71 & 0.39 & 0.72 \\
BK & 0.74 & 0.68 & 0.46 & 0.77 & 0.74 & 0.36 & 0.73 \\
CF & 0.68 & 0.75 & 0.52 & 0.75 & 0.68 & 0.46 & 0.75 \\
BW & 0.65 & 0.75 & 0.54 & 0.72 & 0.65 & 0.49 & 0.74 \\
Clark & 0.71 & 0.34 & 0.26 & 0.83 & 0.71 & 0.10 & 0.77 \\
Rodríguez & 0.87 & 0.36 & 0.40 & 0.68 & 0.87 & 0.09 & 0.67 \\
Hamilton & 0.33 & 0.45 & 0.45 & 0.68 & 0.34 & 0.12 & 0.47 \\
Plucking & 0.88 & 0.31 & 0.33 & 0.81 & 0.88 & 0.12 & 0.81 \\
Promedio & 0.73 & 0.50 & 0.44 & 0.74 & 0.73 & 0.21 & 0.69 \\
\hline Rodriguez & 20) & & & & 0.34
\end{tabular}

Rodríguez (2010c) use a multivariate Kalman filter

$t$, lineal trend; $t^{2}$, quadratic trend; $t_{q 1}$, lineal trend with break in level (1990q3); $t_{q 2}$, linear trend with break in level (1990q3) and slope (2002q1)
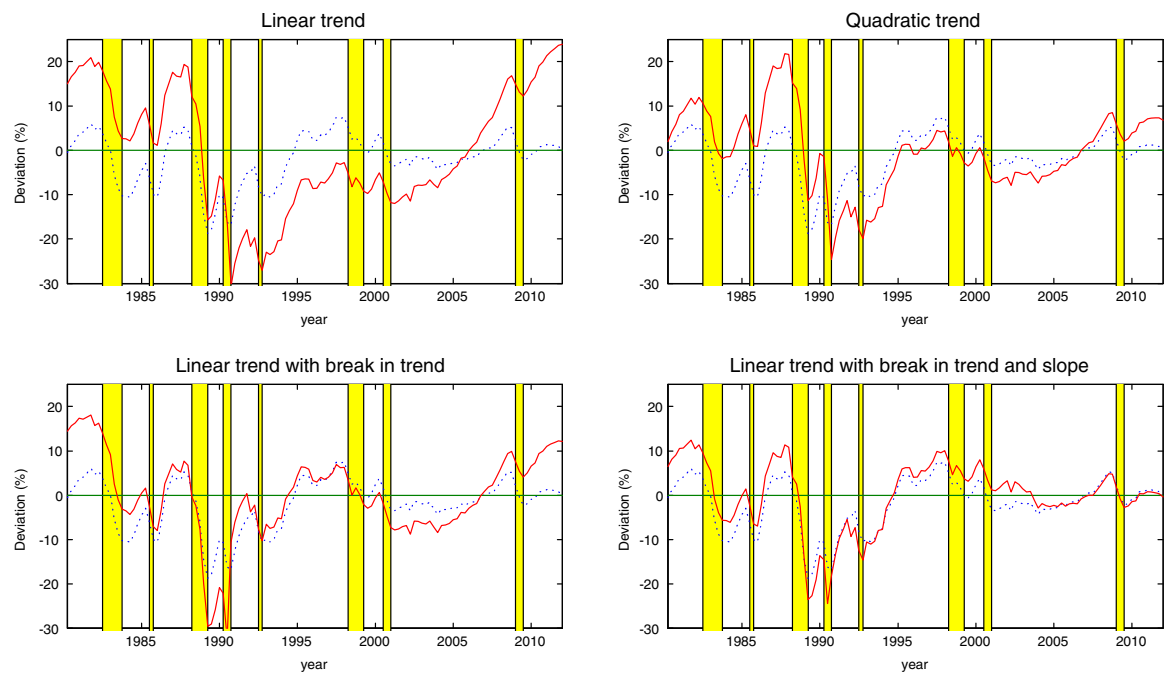

Fig. 5 Cycles of UC-CN model, comparision with others methods

The next models are the trends with break $t_{q_{1}}$ and $t_{q_{2}}$ that show cycles that are more in line with the recessionary periods. Regarding the latter, the higher correlation is obtained with the UC-CN model. An interesting result is a correlation higher than $90 \%$ with the $t_{q_{1}}$ method. This appears to indicate that the trend is almost deterministic most of the time, and it only presents discrete changes in its 

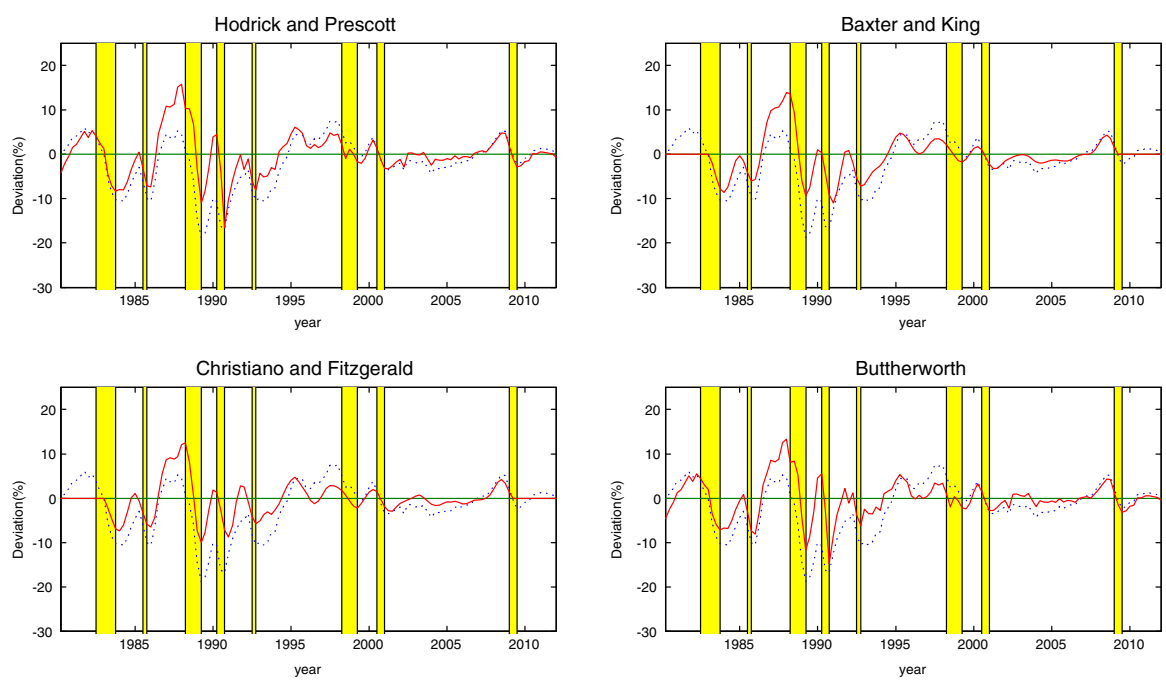

Fig. 6 Cycles of UC-CN model, comparision with others methods

level when facing structural adjustment processes or reforms such as those of 1990 and 2002.

The next four methods in the table correspond to statistical filters. HP 1600 is the Hodrick and Prescott (1997) filter with a smoothing parameter of 1600, ByK is the Baxter and King (1999) filter, and CyF is the Christiano and Fitzgerald (2003) filter, whereas BW is a Butterworth filter similar to that proposed by Harvey and Timbur (2003). These filters produce cycles that are very similar to each other, but the ByK and CyF filters show smoother cycles due to their band-pass nature. Th highest correlation of these filters, with the exception of the BW filter, occurs with the model UC-CN. The comparison of this model with the featured filters is shown in Fig. 6.

Finally, we carry out a comparison with econometric "filters" that model the GDP series on the basis of theoretical fundamentals or empirical regularities. We estimated the univariate model of non-observable components of Clark (1987), the bivariate model of Rodríguez (2010c) which employs a Phillips curve, the Hamilton (1989) model in the state space representation proposed by Kim and Nelson (1999b), and the "plucking" model of Kim and Nelson (1999a). The cycles of each model are shown in Fig. 7, and the highest correlation is given with the cycles generated in the UC-C and UC-CN models.

Summing up this comparison exercise, one can conclude that the UC-CN model obtains the highest correlations with a larger quantity of methods.

In order to statistically assess the good specification of a model, we carried out an analysis of residuals. The residuals correspond to the prediction error of each model and have been normalized with respect to the variance of the prediction error. Several tests have been applied to the residual vector of each model, and the results are shown in Table 5. The first was the Lagrange multiplier test (LM Test) for detecting residual autocorrelation, and it showed that no model rejects the null 

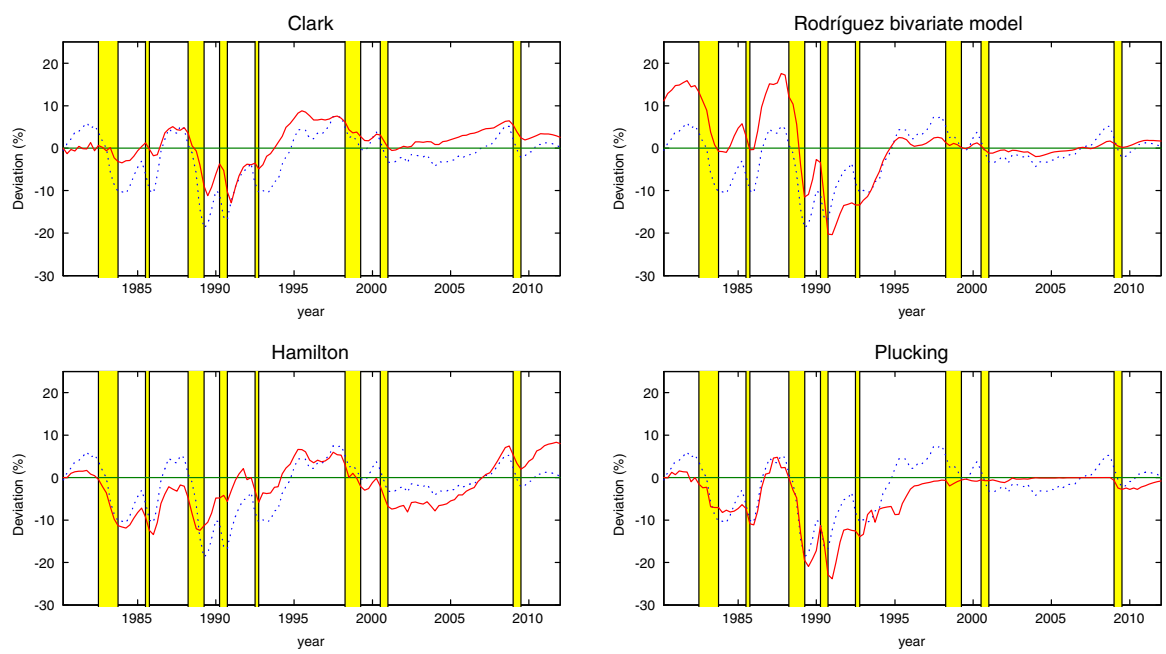

Fig. 7 Cycles of UC-CN model, comparision with others methods

Table 5 Residuals analysis

\begin{tabular}{|c|c|c|c|c|c|c|c|}
\hline Statistic & UC-C & UC-N & UC-P & $\mathrm{UC}-\mathrm{CN}$ & $\mathrm{UC}-\mathrm{CP}$ & UC-NP & $\mathrm{UC}-\mathrm{CNP}$ \\
\hline \multicolumn{8}{|c|}{ Autocorrelation LM Test (p-values) } \\
\hline LM & 0.236 & 0.238 & 0.125 & 0.998 & 0.455 & 0.962 & 0.324 \\
\hline $\mathrm{LM}(1)$ & 0.181 & 0.579 & 0.685 & 0.829 & 0.829 & 0.196 & 0.136 \\
\hline $\operatorname{LM}(2)$ & 0.240 & 0.930 & 0.723 & 0.657 & 0.657 & 0.234 & 0.721 \\
\hline $\operatorname{LM}(3)$ & 0.790 & 0.217 & 0.410 & 0.847 & 0.847 & 0.730 & 0.206 \\
\hline $\operatorname{LM}(4)$ & 0.016 & 0.025 & 0.006 & 0.027 & 0.027 & 0.016 & 0.066 \\
\hline $\mathrm{LM}(5)$ & 0.296 & 0.158 & 0.087 & 0.517 & 0.517 & 0.311 & 0.162 \\
\hline $\operatorname{LM}(6)$ & 0.975 & 0.387 & 0.931 & 0.223 & 0.223 & 0.972 & 0.673 \\
\hline $\operatorname{LM}(7)$ & 0.567 & 0.207 & 0.751 & 0.486 & 0.486 & 0.535 & 0.869 \\
\hline $\operatorname{LM}(8)$ & 0.590 & 0.206 & 0.070 & 0.388 & 0.388 & 0.598 & 0.266 \\
\hline \multicolumn{8}{|c|}{ Autoregressive conditional heteroscedasticity test ( $p$-values) } \\
\hline $\mathrm{ARCH}$ & 0.989 & 0.727 & 0.379 & 0.896 & 0.992 & 0.264 & 0.024 \\
\hline $\mathrm{ARCH}(1)$ & 0.922 & 0.431 & 0.977 & 0.760 & 0.993 & 0.297 & 0.059 \\
\hline $\mathrm{ARCH}(2)$ & 0.916 & 0.926 & 0.168 & 0.723 & 0.898 & 0.253 & 0.111 \\
\hline \multicolumn{8}{|c|}{ Normality test ( $p$-values) } \\
\hline Jarque-Bera & 0.053 & 0.084 & 0.808 & 0.049 & 0.057 & 0.047 & 0.000 \\
\hline \multicolumn{8}{|c|}{ Independence test ( $p$-values) } \\
\hline $\operatorname{BDS}(m=2,0.7)$ & 0.817 & 0.817 & 0.960 & 0.523 & 0.870 & 0.049 & 0.000 \\
\hline $\operatorname{BDS}(m=3,0.7)$ & 0.498 & 0.498 & 0.448 & 0.560 & 0.538 & 0.217 & 0.000 \\
\hline $\operatorname{BDS}(m=4,0.7)$ & 0.345 & 0.345 & 0.179 & 0.654 & 0.350 & 0.507 & 0.000 \\
\hline BDS $(m=5,0.7)$ & 0.404 & 0.404 & 0.124 & 0.662 & 0.379 & 0.875 & 0.000 \\
\hline $\operatorname{BDS}(m=6,0.7)$ & 0.380 & 0.380 & 0.103 & 0.904 & 0.315 & 0.998 & 0.000 \\
\hline
\end{tabular}

Null hypothesis over residuals of LM, ARCH, Jarque-Bera y BDS tests are no autocorrelation, no autoregressive conditional heteroscedasticity, normality and independence, respectively 
Table 6 Information criteria

\begin{tabular}{lllllllll}
\hline & UC-0 & UC-C & UC-N & UC-P & UC-CN & UC-CP & UC-NP & UC-CNP \\
\hline AIC & 632.04 & 630.84 & 632.63 & 649.89 & 603.32 & 610.27 & 622.29 & 636.07 \\
BIC & 649.16 & 653.65 & 655.45 & 672.71 & 631.84 & 638.79 & 650.81 & 670.29 \\
\hline
\end{tabular}

$\mathrm{AIC}=-2 \ln (L)+2 k$, while $\mathrm{BIC}=-2 \ln (L)+\ln (T) k$

hypothesis of non-correlation. The second test was the autoregressive conditional heteroskedasticity in residuals test (ARCH Test). In this case only the UC-CNP model shows ARCH effects in the residuals. The third test was the residual normality test (Jarque-Bera test). Only the UC-CNP model rejects the null hypothesis of normality, whereas the UC-CN, UC-CP and UC-NP models are at the threshold of significance. Finally, the residual independence test (BDS test) was applied, where the null hypothesis implies independence of residuals; in this case only the UC-CNP model rejects independence.

For the selection between models we relied in the first place on information criteria, and secondly on a likelihood ratio according to the specification of Davies (1987). ${ }^{21}$ Table 6 shows the Akaike and Schwartz Information Criteria (AIC and $\mathrm{BIC}$, respectively). The model with the lowest value according to both criteria is UC-CN, whereas the UC-CP model is the second option. On the other hand, Table 7 shows the $p$-values of the likelihood ratio, where each model that contain mixtures of normals is compared with the base and nested models. The null hypothesis is that the restricted model, in this case the nested model, is equivalent to the unrestricted one. The results indicate that the UC-CN and the UC-CP models are superior to the rest.

The results of these tests favor the use of the UC-CN and UC-CP models. However, the UC-CP model would be an over-specification of the UC-C model, since both present the same decomposition. Besides, we found that the UC-CP and UC-C models presented inconsistencies with certain empirical regularities of cycles, such as the total domination of short term shocks ${ }^{22}$, the lack of imaginary roots, and the low correspondence with other usually employed methods. In consequence, we

\footnotetext{
${ }^{21}$ In a non-linear model that presents regimes for certain variables, the maximum likelihood test does not have a standard asymptotical distribution. The problem arises from the fact that some parameters are not identified under the null hypothesis (Andrews and Ploberger 1994). Davies (1987) works under the idea of assigning certain variables to the parameters under the alternative hypothesis and builds a statistic on the basis of these values. A lower bound is thus obtained for the degree of significance of the likelihood ratio test under the null hypothesis. The estimation of this statistic is done following García and Perron (1996), who work with an estimation that is simpler to estimate.

22 For example, Stock and Watson (1988) and King et al. (1991) find that in the case of the United States, both long term and short term shocks are important. Aguiar and Gopinath (2007) find that in the case of developing countries, productivity shocks explain an important portion of output fluctuations. On the other hand, the results of Rodríguez (2010c) show that the variance of the trend component of Peruvian GDP is as important as the variance of the cyclical component, especially from 1990 onwards. Finally, although Perron (1989) and Perron and Wada (2009) propose a non-stochastic trend for most of the time, this goes in hand with structural changes in the trend during some periods; however, this is not the case in the UC-C and the UC-CP models.
} 
Table 7 Likelihood ratio test ( $p$ values)

\begin{tabular}{lcccrrrr}
\hline & UC-C & UC-N & UC-P & UC-CN & UC-CP & UC-NP & UC-CNP \\
\hline UC-0 & 0.514 & 0.754 & & 0.001 & 0.012 & 0.823 & 1.000 \\
UC-C & & & & 0.000 & 0.000 & & 1.000 \\
UC-N & & & & 0.000 & & 0.022 & 1.000 \\
UC-P & & & & & 0.000 & 0.000 & 0.221 \\
$\ln (L)$ & -307.42 & -308.32 & -316.95 & -291.66 & -295.13 & -301.14 & -306.03 \\
\hline
\end{tabular}

Results in p-values following Davies' specification (1987)

consider that the UC-CN model is the most appropriate in order to identify the cycles of the Peruvian economy.

\section{Conclusions}

From 1980 to the present, different recessions and expansions took place with varying magnitude and duration. Moreover, a series of structural reforms were carried out, which changed the dynamic of output in the long term. This irregular pattern of Peruvian GDP leads to non-linearities in the long-term component and to asymmetries in the cycles.

Multiple methods to estimate trend and cycles of the Peruvian economy have been used; linear methods, either univariate or multivariate, tend to underestimate the recessionary cycles or overestimate the expansionary cycles, especially in the period before the structural reforms of the early 1990s. On the other hand, the nonlinear methods such as Markov switching identify adequately the periods of big recessions, but they lose power in identifying the recessions after 1990.

Two facts act against these two types of methods. First, they assume symmetrical cycles, which conditions the decomposition to recession or boom periods of similar magnitude, whereas empirical evidence shows the opposite. Second, the structural reforms of the early 1990s implied a profound change in the behavior of GDP, so that it is not useful to assume a Markov process for the entirety of the series.

In view of this evidence, we applied the methodology developed in Wada and Perron (2006) and Perron and Wada (2009) to the estimation of the trend and cycle of the Peruvian GDP. This model contemplates the presence of a mixture of normal distributions in the terms of disturbance, generating regimes of high and low variance. Starting from this specification, there may arise abrupt changes in the trend level that are associated with adjustment periods or with structural reforms, as well as to an asymmetric evolution of the cyclical component.

The methodology hereby applied is flexible and the results are in line with the literature and with the evidence supporting non-linearities in output and asymmetries in the cycles. Seven univariate models were estimated, with different setups of mixture of normals. The estimations maintain certain regularities with respect to the behavior of the trend and cycles in the Peruvian economy. For example, before the 1990s, the cycles show higher amplitude and the periods of high volatility in either 
the cycle or the trend are more frequent. In contrast, in the years after 2000, there is a general decrease in the probabilities of being in a high volatility regime and the cycles have a lower amplitude. Finally, the slope or long term growth rate has been increasing and has reached its highest level in the last years.

In order to select the best model, economic and statistical analyses were performed. Regarding the former, the results of each model were compared with certain empirical regularities of economic fluctuations, such as the cyclical pattern that the short term component must keep, the importance of long and short term shocks, as well as a sensitivity analysis with other traditionally used methods. Regarding the latter, an evaluation of residuals, the application of information criteria and an adequate likelihood ratio test were carried out.

On the basis of this assessment, the UC-CN model shows the best performance allowing for small changes in the trend level and asymmetries in the cyclical component. For example, it identifies correctly the structural change of the early 1990s. Moreover, the visual inspection of cycles against recessionary periods is in line with the behavior or Peruvian GDP in the last 30 years, so that this new method can constitute a useful tool in the measurement of cycles of the Peruvian economy.

In specific terms, this model reveals some relevant facts on the last recessions. First, the output gap of 2008 before the economic crisis was one of the largest in the last decades. Second, a drop in the expansive cycle is reported, starting with the 1998 crisis and a negative cycle in 2000. During that period, a slight decrease in the long term growth rate and volatility in the trend were observed, which is taking into consideration that the 1998 crisis brought about a banking crisis as well. Third, the largest negative gaps were reported during the late 1980s and the early 1990s.

Finally, the relative weight of short and long terms shocks was estimated. Both in the selected model as in the rest, a regularity takes hold: the short term cycles are important elements in explaining the fluctuations of output. Due to this, short term policies such as monetary or fiscal measures are relevant and can assist in reversing a recessive cycle or dampening a rapid expansion.

The current research can be extended in several directions. First into a multivariate level, for example by incorporating a Phillips curve or the relationship with unemployment by means of Okun's law. Second, the inclusion of the mixture of normals can be applied to other series and be used in the construction of composite indices of the economy or leading indicators. The use of Bayesian techniques can also be included.

Open Access This article is distributed under the terms of the Creative Commons Attribution License which permits any use, distribution, and reproduction in any medium, provided the original author(s) and the source are credited.

\section{References}

Aguiar M, Gopinath G (2007) Emerging market business cycles: the cycle is the trend. J Polit Econ 115:69-102

Andrews D, Ploberger W (1994) Optimal tests when a nuisance parameter is present only under the alternative. Econometrica 62:1383-1414 
Apel M, Jansson P (1999) A theory-consistent system approach for estimating potential output and the NAIRU. Econ Lett 64:271-75

Basistha A (2007) Trend-cycle correlation, drift break and the estimation of trend and cycle in Canadian GDP. Can J Econ 40:584-606

Basistha A, Nelson CR (2007) New measures of the output gap based on the forward-looking new Keynesian Phillips curve. J Monet Econ 54:498-511

Baxter M, King RG (1999) Measuring business cycles: approximate band-pass filter for economic time series. Rev Econ Stat 79:551-563

Beveridge S, Nelson CR (1981) A new approach to descomposition of economic time series into permanent and transitory components with particular attention to measurement of the 'business cycle'. J Monet Econ 7:151-174

Blanchard OJ, Quah D (1989) The dynamic effects of aggregate demand and supply disturbances. Am Econ Rev 79:655-673

Box GEP, Jenkins GM (1976) Time series analysis forecasting and control. Holden-Day, San Francisco

Burns AF, Mitchell WC (1946) Measuring business cycles. National Bureau of Economic Research, New York

Cabredo p, Valdivia L (1999) Estimación del PBI Potencial: Perú 1950 - 1997. Revista de Estudios Económicos 5

Canova F (1998) Detrending and business cycle facts. J Monet Econ 41:475-512

Campbell JY, Mankiw NG (1987) Are output fluctuations transitory?. Q J Econ 102:857-880

Castillo P, Montoro C, Tuesta F (2007) Hechos Estilizados de la Economía Peruana. Revista de Estudios Económicos 14:33-75

Christiano LJ, Fitzgerald TJ (2003) The band pass filter. Int Econ Rev 44:435-465

Clark PK (1987) The cyclical component of U.S. economic activity. Q J Econ 102:797-814

Cochrane J (1988) How big is the random walk in GNP?. J Polit Econ 96:893-920

Dancourt O, Mendoza W, Vilcapoma L (1997) Fluctuaciones económicas y shocks externos, Perú 1950-1996. Documento de Trabajo PUCP 135

Dancourt O, Mendoza W (2009) Perú 2008-2009: del auge a la recesión: choque externo y espuestas de políticas macroeconómicas," en Crisis internacional: Impactos and respuestas de política económica en el Perú., ed. Dancourt, O., F. Jimenez, Fondo Editorial PUCP, Lima

Davies RB (1987) Hypothesis testing when a nuisance parameter is present only under the alternative. Biometrika 74:33-43

Dickey DA, Fuller WA (1979) Distribution of the estimators for autoregressive time series with a unit root. J Am Stat Assoc 74:427-431

Diebold FX, Rudebusch GD (1990) A nonparametric investigation of duration dependence in the American business cycle. J Polit Econ 98:596-616

Diebold FX, Rudebusch GDSichel D (1993) Further evidence on business-cycle duration dependence. Business cycles, indicators and forecasting, University of Chicago Press, Chicago

Doménech R, Gómez V (2006) Estimating potential output, core inflation, and the NAIRU as latent variables. J Bus Econ Stat 24(3):354-365

Elliott G, Rothenberg TJ, Stock JH (1996) Efficient tests for an autoregressive unit root. Econometrica 64:813-836

Fellner W (1956) Trends and cycles in economic activity. Henry Holt, New York

Friedman M (1957) A theory of the consumption function. Princeton University Press, Princeton

Friedman M (1964) Monetary studies of the National Bureau. The National Bureau enters its 45th year, 44th Annual Report, 7-25

Friedman M (1993) The 'plucking model' of business fluctuations revisited. Econ Inq 31(2):171-177

Garcia R, Perron P (1996) An analysis of the real interest rate under regime shifts. Rev Econ Stat 78:111-125

Goodwin TH (1993) Business-cycle analysis with a Markov-switching model. J Bus Econ Stat 11:331-339

Guillén Á, Rodríguez G (2013) Trend-cycle decomposition for Peruvian GDP: application of an alternative method. Working Paper, Department of Economics, Pontificia Universidad Católica del Perú

Haggan V, Ozaki T (1981) Modeling nonlinear random vibrations using an amplitude-dependent autoregressive time series model. Biometrika 68:189-196

Hamilton JD (1989) A new approach to the economic analysis of nonstationary time series and the business cycle. Econometrica 57:357-384 
Hamilton JD, Waggoner DF, Zha T (2004) Normalization in econometrics. Econ Rev 26:221-252

Harrison PJ, Stevens CF (1976) Bayesian forecasting. J R Stat Soc Ser B 38:205-247

Harvey AC (1989) Forecasting, structural time series models and the Kalman filter. Cambridge University Press, Cambridge

Harvey AC, Jaeger A (1993) Detrending, stylized facts and the business cycle. J Appl Econ 8:231-241

Harvey AC, Phillips GDA (1979) The estimation of regression models with autoregressive-moving average disturbances. Biometrika 66:49-58

Harvey AC, Trimbur TM (2003) General model-based filters for extracting cycles and trends in economic time series. Rev Econ Stat 85:244-255

Hodrick R, Prescott E (1997) Postwar US business cycles: an empirical investigation. J Money Credit Bank 29:1-16

Kim CJ, Nelson CR (1999a) Friedman's plucking model of business fluctuations: tests and estimates of permanent and transitory components. J Money Credit Bank 31:317-334

Kim CJ, Nelson C (1999b) State-space models with regime switching. MIT Press, Cambridge

King RG, Plosser CI, Stock JH, Watson MW (1991) Stochastic trends and economic fluctuations. Am Econ Rev 81:819-840

Kitagawa G (1987) Non-Gaussian state-space modeling of nonstationary time series. J Am Stat Assoc 82:1032-1063

Krolzig HM (1997) Markov-switching vector autoregressions. Modelling, statistical inference, and application to business cycle analysis. Lecture notes in economics and mathematical systems, vol 454. Springer, Berlin

Kuttner NK (1994) Estimating potential output as a latent variable. J Bus Econ Stat 12:361-368

Laubach T (2001) Measuring the NAIRU: evidence from seven economies. Rev Econ Stat 83(2):218-231

Marfán M, Artiagoitia P (1989) Estimación del PGB potencial: Chile 1960-1988. Colección de Estudios Cieplan, Diciembre 1989

Miller S (2003) Métodos Alternativos para la Estimación del PBI potencial: Una aplicación para el caso de Perú. Revista de Estudios Económicos 10

Mills TC, Wang P (2002) Plucking models of business cycle fluctuations: evidence from the G-7 countries. Empir Econ 25:225-276

Morley JC, Nelson CR, Zivot E (2003) Why are the Beveridge-Nelson and unobserved-components decompositions of GDP so different?. Rev Econ Stat 85:235-243

Murray CJ (2003) Cyclical properties of Baxter-King filtered time series. Rev Econ Stat 85:472-476

Muth JF (1960) Optimal properties of exponentially weighted forecasts. J Am Stat Assoc 55:299-306

Nelson CR, Plosser CI (1982) Trends and random walks in macroeconomic time series. J Monet Econ 10:139-162

Neftci SN (1984) Are economic time series asymmetric over the business cycles?. J Polit Econ 92(2):307-328

Ochoa E, Lladó J (2003) Modelos de indicadores líderes de actividad económica para el Perú. Revista de Estudios Económicos 10

Oh K, Zivot E (2006) The Clark model with correlated components. Manuscrito no publicado

Perron P (1989) The great crash, the oil price shock and the unit root hypothesis. Econometrica 57:1361-1401

Perron P, Wada T (2009) Let's take a break: trends and cycles in US real GDP. J Monet Econ 56:749-765

Rodríguez G (2010a) Application of three non-linear econometric approaches to identify business cycles in Peru. OECD J J Bus Cycle Meas Anal 2:1-25

Rodríguez G (2010b) Using a forward-looking Phillips curve to estimate the output gap in Peru. Rev Appl Econ 10:149-160

Rodríguez G (2010c) Estimating output gap, core inflatión, and the NAIRU for Peru, 1979-2007. Appl Econ Int Dev 10:149-160

Said S, Dickey D (1984) Testing for unit roots in autoregressive-moving average models of unknown order. Biometrika 71:599-607

Seminario B, Rodríguez M, Zuloeta J (2007) Métodos Alternativos para la Estimación del PBI Potencial 1950-2007. Documento de Discusión DD/07/20 UP

Sichel DE (1991) Business cycle duration dependence: a parametric approach. Rev Econ Stat 73:254-260

Sichel DE (1993) Business cycle asymmetry: a deeper look. Econ Inq 31(2):224-236

Stock JH, Watson MW (1988) Variable trends in economic time series. J Econ Perspect 2:147-174

Tsay R (1989) Testing and modeling threshold autoregressive processes. J Am Stat Assoc 84:231-240 
Teräsvirta T, Anderson HM (1992) Characterizing nonlinearities in business cycles using smooth transition autoregressive models. J Appl Econom 7:S119-S136

Teräsvirta T (1994) Specification, estimation, and evaluation of smooth transition autoregressive models. J Am Stat Assoc 89:208-218

Wada T, Perron P (2006) An alternative trend-cycle decomposition using a state space model with mixtures of normals: specifications and applications to international data. Boston University Working Paper 2005-44 Versió n Septiembre 2006

Watson MW (1986) Univariate detrending methods with stochastic trends. J Monet Econ 18:49-75

Zamowitz V, Boschan C (1977) Cyclical indicators. National Bureau of Economic Research 57th Annual Report, pp 34-38 